\title{
Functional Outcomes of Cerebellar Malformations
}

\author{
Jason S. Gill1,2,3 and Roy V. Sillitoe ${ }^{2,3,4 * t}$ \\ ${ }^{1}$ Section of Pediatric Neurology and Developmental Neuroscience, Baylor College of Medicine, Houston, TX, United States, \\ ${ }^{2}$ Department of Pathology and Immunology, Baylor College of Medicine, Houston, TX, United States, ${ }^{3}$ Jan and Dan Duncan \\ Neurological Research Institute of Texas Children's Hospital, Houston, TX. United States, ${ }^{4}$ Department of Neuroscience, \\ Baylor College of Medicine, Houston, TX, United States
}

\section{OPEN ACCESS}

Edited by:

Orly Reiner,

Weizmann Institute of Science, Israel

Reviewed by: Julián Benito León, University Hospital October 12, Spain Vikram Shakkottai, University of Michigan, United States

${ }^{*}$ Correspondence: Roy V. Sillitoe sillitoe@bcm.edu

tORCID:

Roy V. Sillitoe orcid.org/0000-0002-6177-6190

Specialty section: This article was submitted to

Cellular Neurophysiology, a section of the journal Frontiers in Cellular Neuroscience

Received: 31 July 2019 Accepted: 18 September 2019

Published: 04 October 2019

Citation:

Gill JS and Sillitoe RV (2019) Functional Outcomes of Cerebellar Malformations.

Front. Cell. Neurosci. 13:441. doi: 10.3389/fncel.2019.00441
The cerebellum is well-established as a primary center for controlling sensorimotor functions. However, recent experiments have demonstrated additional roles for the cerebellum in higher-order cognitive functions such as language, emotion, reward, social behavior, and working memory. Based on the diversity of behaviors that it can influence, it is therefore not surprising that cerebellar dysfunction is linked to motor diseases such as ataxia, dystonia, tremor, and Parkinson's disease as well to non-motor disorders including autism spectrum disorders (ASD), schizophrenia, depression, and anxiety. Regardless of the condition, there is a growing consensus that developmental disturbances of the cerebellum may be a central culprit in triggering a number of distinct pathophysiological processes. Here, we consider how cerebellar malformations and neuronal circuit wiring impact brain function and behavior during development. We use the cerebellum as a model to discuss the expanding view that local integrated brain circuits function within the context of distributed global networks to communicate the computations that drive complex behavior. We highlight growing concerns that neurological and neuropsychiatric diseases with severe behavioral outcomes originate from developmental insults to the cerebellum.

Keywords: cerebellum, development, Purkinje cell, cerebellar nuclei, circuitry, motor, cognitive

\section{INTRODUCTION}

Human behavior is seemingly infinite in its functional complexity, yet the human brain is capable of synthesizing sophisticated movements, motivations, emotions, and desires with fluid continuity and into a multitude of distinct, recognizable behaviors. Furthermore, major disruptions affecting large portions of the brain or minor alterations that only subtly set its neural function askew are all immediately evident during disease pathogenesis with the full spectrum of neurological and neuropsychiatric disease readily manifest in altered behavior. How the brain achieves this remarkably robust yet at times fragile integration of sensorimotor and executive function remains a mystery that requires the full intent of neuroscientific inquiry. Despite this monumental task, the synthesis of molecular, cellular, systems, and clinical neuroscience has helped to continuously push our knowledge forward. The cerebellum, now regarded as a central node for the integration of diverse circuit functions, is an interesting starting point to understand how the brain computes and produces the symphonic elegance that characterizes animal behavior.

The cerebellum has traditionally been regarded solely as a regulator of motor function (Manto et al., 2012; Perciavalle et al., 2013; Lang et al., 2017). Over the past several decades, however, 
a consensus is forming regarding a role for the cerebellum in non-motor behavior, the precise nature of which has yet to be fully elucidated (Koziol et al., 2014; Mariën et al., 2014; Baumann et al., 2015). Turning to clinical observations and literature, a central role for the cerebellum in cognitive function was posited almost 30 years ago (Schmahmann, 1991). In the context of the highly articulated and patterned nature of the cerebellar cortex as well as experimental and clinical observations, the idea of the universal cerebellar transform was conceived (Schmahmann, 2004): motor dysfunction related to cerebellar pathology can manifest as ataxia, dysmetria, dystonia, and tremor, while the cognitive or affective manifestations of these incoordinations may be reflected in pseudobulbar palsy, disinhibition, inattention, and psychosis (Schmahmann, 2004). This mirroring of motor dysfunction in the affective/cognitive sphere is a concept referred to as dysmetria of thought. Thus, regardless of whether the cerebellum is involved in a motor or non-motor behavior, its role in coordinating and integrating different functional modalities is compromised upon insult, and perhaps the compromise of a "universal" neural computation is at fault. This raises at least two intriguing questions: (1) What is the cerebellar circuit architecture that mediates its many functions? (2) Are cerebellar circuits heterogeneous?

Using the cellular composition and anatomy of the cerebellum as a platform, we discuss how developmental, genetic, and mechanical cerebellar disruptions influence circuit assembly and ultimately impact motor and non-motor behavior. To do so, we consider that the cellular composition and cytoarchitecture of the cerebellar cortex, which, while vastly more uniform than the neocortex, is nevertheless anatomically, genetically, and electrophysiologically variable across its microdomains (Cerminara et al., 2015; Apps et al., 2018). The present review will elide the discussion of cerebellar function as a universal cerebellar transform or multiple functionality, instead considering a modified version of the universal cerebellar transform such that as the cerebellum expanded through evolutionary time, it adapted to the increasing requirements associated with behavioral complexity, and concordantly its microarchitecture evolved to have specialized functions that subserve distinct cortical areas. At the same time, the cerebellum would have preserved its role in integrating afferent sensory information from the periphery, namely sensory modalities such as vestibular pathways that are evolutionarily wellconserved. There is a possibility that sensorimotor functions are executed by the same circuits that modulate cognitive behaviors (Diedrichsen et al., 2019). In this scenario, the heterogenous anatomy and functional properties of the internal cerebellar microcircuitry could provide such flexibility to occur (Reeber et al., 2013; Beckinghausen and Sillitoe, 2019; Sathyanesan et al., 2019). The present review will seek to synthesize basic neuroscientific and macro-evolutionary observations with human disease observations to help contextualize current efforts in rodent models aimed at developing a more sophisticated understanding of the role of the cerebellum in cognitive and affective behavior. We focus on how these behavioral entities are influenced by first examining how the cerebellum develops its precisely patterned internal architecture and how this cerebellar map drives the assembly and functional architecture of its topographic circuits.

\section{CEREBELLAR CYTOARCHITECTURE AND BASIC CIRCUITRY}

In addition to the first descriptions of the Purkinje cell by Johannes Evangelista Purkinje and the potential interactions between cell types suggested by Camillo Golgi using his classic reazione nera or "the black reaction" (described in Herndon, 1963), the earliest extensive descriptions of the complete and precise cellular cytoarchitecture of the cerebellum come from the original studies of Ramon y Cajal, who both revolutionized our understanding of the organization of the nervous system and provided a basis for our current understanding of neuronal transmission (for a review of Cajal's early findings; see Sotelo, 2008). It is from these pioneering descriptions of Purkinje, Golgi, Cajal and others that the orthodoxy of the uniform cytoarchitecture of the cerebellum arose. It should be noted that Cajal's findings on the localization and morphology of the different cell types have remained relevant to present day, though with several specialized features of the circuit recently unveiled (e.g., the identification of unipolar brush cells, direct projections from Purkinje cells to granule cells, and the nucleo-cortical projections). In the past 60 years, our understanding of the cytoarchitecture of the cerebellum has thus greatly expanded (Glickstein and Voogd, 1995; Voogd and Glickstein, 1998; Oberdick and Sillitoe, 2011; Ruigrok, 2011; Voogd and Koehler, 2018), with an overarching theme being the demonstration of cellular and circuit heterogeneity.

\section{A Primer on Cerebellar Circuitry}

To appreciate how the cerebellum functions and how it fails in disease, it is useful to recall that connectivity within the cerebellum is understood at a considerable level of detail, with each cell type forming stereotypical connections with its neighbors (Figure 1). The cerebellum has three distinct layers. The most superficial layer, the molecular layer, contains inhibitory interneurons and excitatory climbing fibers. Both project onto the dendritic arbors of Purkinje cells, the cell bodies of which occupy the middle layer called the Purkinje cell layer. The Purkinje cells perform the main computations of the cerebellum. Sandwiched between the Purkinje cells are the very large Bergmann glia. It is important to note that the cerebellar glia are highly heterogenous, although poorly studied (Sotelo and Alvarado-Mallart, 1987; Buffo and Rossi, 2013; Goertzen and Veh, 2018; Wizeman et al., 2019). The Purkinje cell layer also contains interneurons called candelabrum cells. The deepest layer is called the granular layer and it contains billions of excitatory neurons called granule cells as well as the terminals of excitatory mossy fibers that deliver sensory signals to the cerebellar cortex. The granule cell axons, which bifurcate into parallel fibers, are located within the molecular layer. The granular layer 


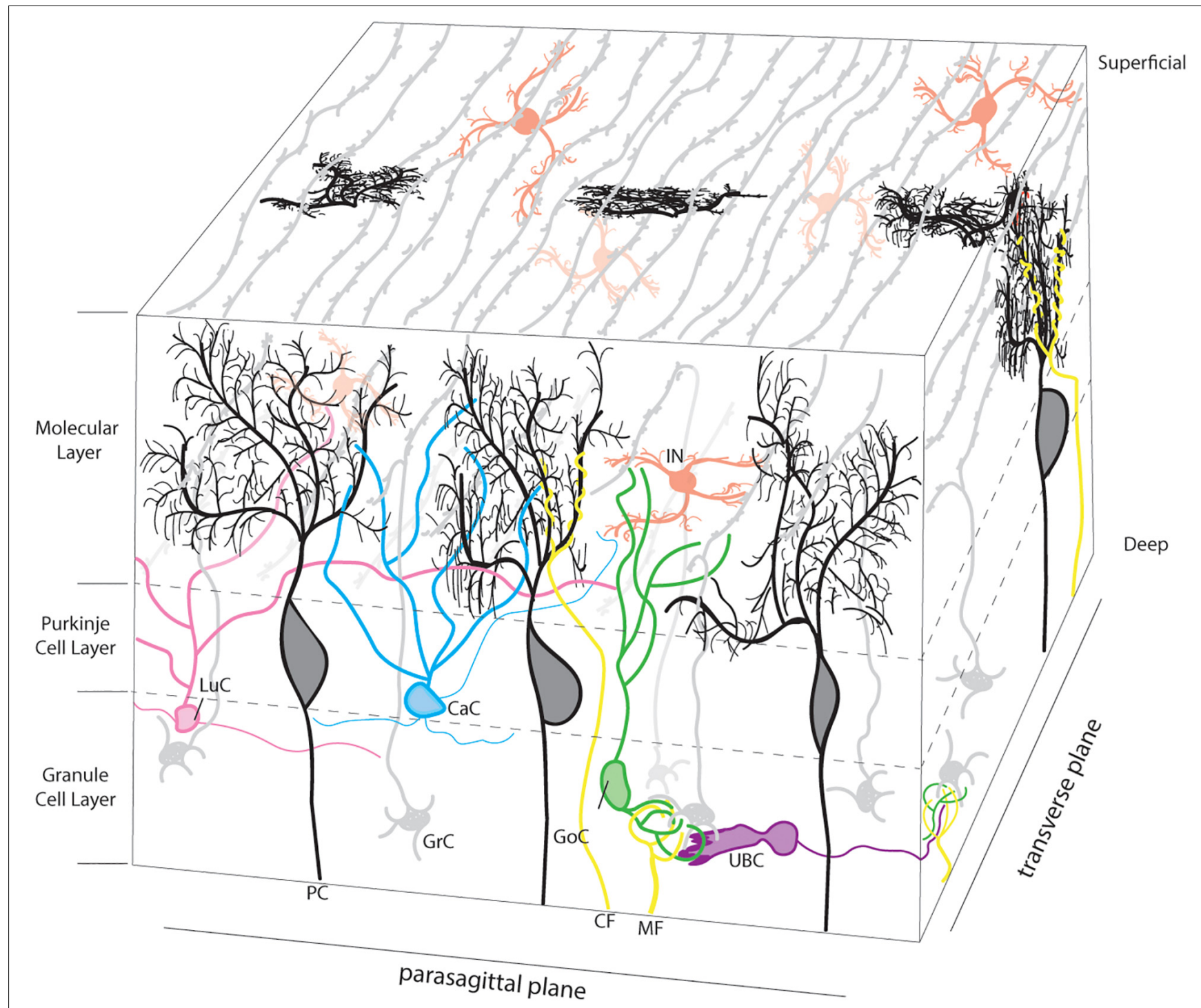

FIGURE 1 | Neuronal microarchitecture of the cerebellar cortex. Representative schema of the layers of the cerebellar cortex. Afferent projections are presented in yellow. Climbing fibers (CF; yellow) project to the molecular layer and target the dendritic tree of a single Purkinje cell (PC; black). Mossy fibers (MF; yellow) terminate in the granule cell layer, forming synaptic connections with granule cells (GrC; gray). The granule cell layer also contains golgi cell (GoC; green), Lugaro cell (LuC; pink), and unipolar brush cell (UBC; purple) interneurons. The cell bodies of granule cells are located in the granule cell layer and project axons to the molecular layer where they branch to form parallel fibers, which run orthogonal to the parasagittal plane. The molecular layer contains the cell bodies of inhibitory interneurons (IIN; red), which include both basket and stellate cells as well as neurites from a variety of neurons, as pictured. Finally, the Purkinje cell layer is occupied by the large cell bodies of the Purkinje cell (PC; black) and the smaller cell bodies of the Candelabrum cells (CaC; Cyan). In 3-dimensional space, the transverse projections of the parallel fibers can integrate and process the afferent information supplied by the climbing and mossy fibers. Basket cell axons, which wrap the Purkinje cell soma and initial segment of the axon, and Bergmann glia palisades that extend into the molecular layer were intentionally excluded to focus on the Purkinje cell anatomy.

also contains inhibitory Golgi cell interneurons, Lugaro cells, and a unique population of excitatory interneurons called unipolar brush cells. The unipolar brush cells are localized mainly in the vermis of lobules IX and $\mathrm{X}$, with a smaller number localized to lobules VI and VII. Although the primary afferent classes are climbing fibers and mossy fibers, there are also modulatory "beaded" fibers that terminate in all layers of the cerebellar cortex and in all ten lobules of the vermis and hemispheres. Below the three layers is a dense network of fiber tracts. Embedded in this network are the cerebellar nuclei (Figure 2A; left panel). The cerebellar nuclei contain specialized neurons that transmit the final output of the cerebellum. Each nucleus is comprised of GABAergic, glycinergic, and glutamatergic cell types. The nuclei are described by their anatomical position in rodents, medial, intermediate and lateral. In primates, the nomenclature is different based on historical anatomic descriptions: the medial nucleus is called fastigial, the intermediate is comprised of the distinct globose and emboliform nuclei which together constitute the interposed nucleus (Figure $\mathbf{2 A}$; inset), and the lateral is called 
the dentate, which in primates has a complex, convoluted structure (Figure 2A; inset). Together, the cerebellar nuclei link the cerebellar cortex to the rest of the brain and spinal cord (Figure 2A; right panel).

\section{CEREBELLAR HETEROGENEITY: ZONES AND TOPOGRAPHY}

The described cerebellar circuitry represents the underlying cellular microstructure that supports the computational domains of the cerebellum, which are comprised of zones (Miterko et al., 2018) that serve to integrate sensorimotor information into executive output, both motor and cognitive. In the second half of the twentieth century, great advances were made in elucidating the circuits of the cerebellum, culminating in the conceptualization of cerebellar modules which were initially based on precise characterizations of the neuroanatomy of the cerebellum (Voogd, 2011). During this time, characterization of afferent olivocerebellar projections to the cerebellar hemispheres as well as efferent dentatothalamocortical projections revealed a parasagittal zonal architecture (van Rossum, 1969; Courville et al., 1974; Matsushita and Wang, 1987). These anatomical findings accompanied the first molecular characterization of the parasagittal zonal configuration of Purkinje cells using $5^{\prime}$ nucleosidase (Scott, 1963). This would be a herald to the molecular delineation and characterization of the cerebellum, the knowledge of which has been vastly expanded with function and molecular genetics over the last 40 years (Apps and Hawkes, 2009).

The most well characterized molecular marker of cerebellar zones is Zebrin II (Hawkes and Leclerc, 1987; Brochu et al., 1990; Ahn et al., 1994). Zebrin II is expressed by a subset of Purkinje cells in highly conspicuous and evolutionarily conserved parasagittal bands (Figure 2B; left panel; Sillitoe et al., 2004; Apps and Hawkes, 2009). Initial characterizations of Zebrin II refined the anatomical descriptions of the zonal architecture of the cerebellum (Voogd et al., 2003), revealing a complex parasagittal organization with diverging and coalescing molecularly defined longitudinal zones. Further supporting a notion that the parasagittal zonal organization is a functional component of the cerebellum, numerous additional molecules expressed in subsets of Purkinje cells have been found to colocalize with Zebrin II (e.g., EAAT4, PLC $\beta 3$; Dehnes et al., 1998; Sarna et al., 2006), or to have a complementary staining pattern to Zebrin II (e.g., mGluR1 $\beta$, PLC $\beta 4$; Mateos et al., 2001; Sarna et al., 2006). While less thoroughly characterized, there is also patterned expression of molecules expressed in cerebellar interneurons, namely the unipolar brush cells, granule cells, and Golgi cells (Consalez and Hawkes, 2013).

As described above, the initial observations of zonal architecture of the cerebellum were anatomic rather than molecular, yet subsequent analyses would buttress the initial anatomic observations with molecular data that helps to elucidate the functional role of the zonal architecture. In addition, numerous studies have contributed to an understanding of zonal architecture whereby there is a segregation of afferent projections, including both mossy fibers and climbing fibers, that have a complex correspondence to the parasagittal organization of Purkinje cell zones (Sugihara, 2004; Pijpers et al., 2006; Sawada et al., 2008; Armstrong et al., 2009; Paukert et al., 2010; Gebre et al., 2012). The parasagittal zonal architecture of the cerebellum doesn't independently comment on the nature of the computations performed by the cerebellar modules. In fact, modules integrating diverse afferent information may be elegant loci in which integrative computations are performed, such as those called for in embodied cognition (Guell et al., 2018). Consistent with the anatomic observations in which there are entire populations of cell types that have restricted localization along the anterior-posterior axis in the cerebellum (Braak and Braak, 1993; Mugnaini and Floris, 1994), there are also Purkinje cell specific molecular markers that have restricted expression along the anterior-posterior axis, namely D3 dopamine receptor, dopamine transporter (DAT), and synaptic vesicular monoamine transporter (VMAT) (Kim Y.S. et al., 2009). Further investigations into the functional relevance of these indices of cerebellar heterogeneity may offer insight into how the cerebellum integrates or processes the wide range of afferent information that it receives.

As might be expected, given the anatomic and molecular heterogeneity found across the cerebellum, the neurophysiology of the cerebellar cortex is not uniform. Corresponding to the variation in D3, DAT, and VMAT along the anterior-posterior axis (Kim Y.S. et al., 2009), there are high levels of depolarization induced slow currents (DISCs) in the Purkinje cells of the posterior lobe vermis while they are seen only at low levels in the Purkinje cells of the anterior vermis (Shin et al., 2008). In addition, Purkinje cells in lobules III/IV have differences in passive and active membrane properties as compared to those in lobule X, resulting in lobule X Purkinje cells being less excitable and displaying a greater variety of firing patterns in response to depolarizing currents (Kim et al., 2012). Finally, even functional connectivity has been shown to vary based on anatomic location, with the finding that there is direct inhibition of granule cells by Purkinje cells in a lobule dependent manner (Guo et al., 2016).

In the mediolateral axis, it has been shown that activation of mGluR and the associated synaptic plasticity in response to complex spikes is reduced in Zebrin II + Purkinje cells (Wadiche and Jahr, 2005), and is most likely mediated by EAAT4 expression and function (Brasnjo and Otis, 2001). Furthermore, the firing properties of Purkinje cells vary based on whether they are located in Zebrin II + or Zebrin II zones (Xiao et al., 2014; Zhou et al., 2014), although these distinctions may occur in a region specific manner rather than being a general feature of Zebrin II \pm zones throughout the cerebellar cortex. Moreover, it remains unclear how zones relate to behavior (Horn et al., 2010; Cerminara and Apps, 2011), particularly whether each zone has a dedicated behavior (or set of behaviors) and if a given zone can contribute to both motor and non-motor behavior. Regardless, it seems plausible that a segmentation of the cerebellum into a map could provide the flexibility through which different behaviors are executed. Having provided an overview of the micro and macro 

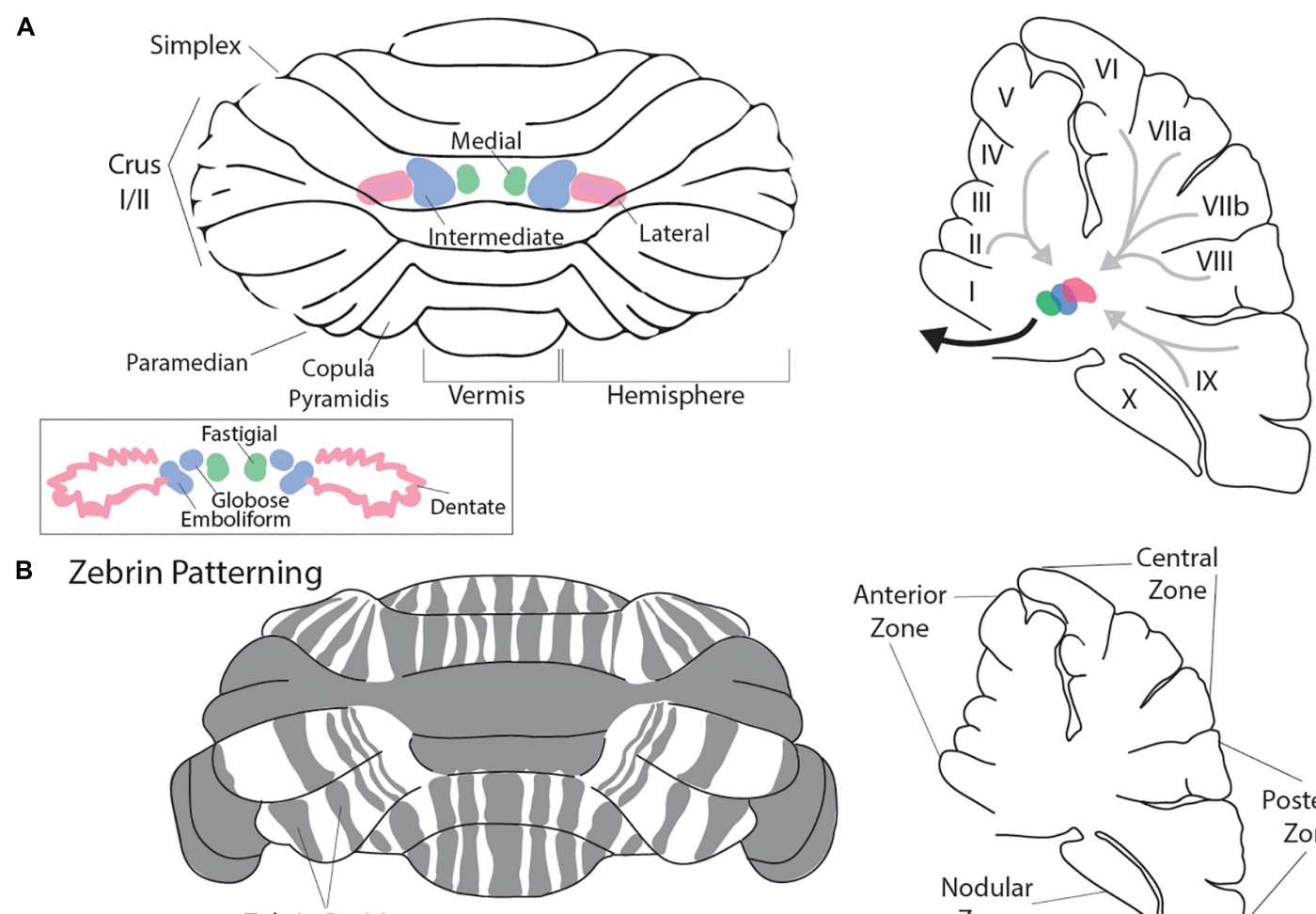

Zebrin Positive

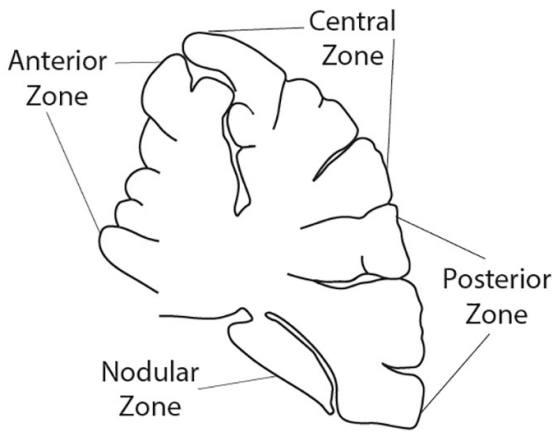

FIGURE 2 | Macroarchitecture of the cerebellum. Rodent cerebellum (A) depicted from the dorsal view (left panel). Rostral is superior and caudal is inferior. Vermis is midline. The cerebellar nuclei $(\mathrm{CN})$ are represented in color. In pink is the lateral nucleus, in green is the medial nucleus, and in blue is the intermediate nucleus (A); inset). Pictured are the primate cerebellar nuclei: lateral is the dentate (Pink) where the convoluted shape in comparison to the rodent lateral nucleus can be appreciated, medial is the fastigial (green), and the globose and emboliform nuclei (blue; together forming the interposed nuclei) are pictured and are analogous to the murine intermediate nucleus. The right panel presents a parasagittal view of the cerebellum at midline. The cerebellar nuclei are indicated as in the left panel (adapted in part from Sugihara et al., 1999 permission was obtained from Wiley Online Library). Light gray arrows represent schematized Purkinje cell output to the $\mathrm{CN}$, while the heavy black arrow represents $\mathrm{CN}$ efferent projections to the cerebral cortex and brainstem. Mouse cerebellum (B) depicted from the dorsal view (left panel). Gray indicates representative Zebrin banding pattern. Orientation is as described in (A). The Right panel indicates the mouse cerebellum at midline in the parasagittal plane with zonal nomenclature. Mouse cerebellum adapted from Cerminara et al. (2015). Permission was obtained from Nature research journals.

architectural features of the cerebellum, a discussion of the developmental processes that underlie the elegant structure of the cerebellum follows.

\section{GENES, MOLECULES, AND MORPHOGENESIS DURING CEREBELLAR DEVELOPMENT}

There are several morphogenetic stages that form the cerebellum. The neural tube divides into morphological divisions called neuromeres, including the forebrain, midbrain, and hindbrain. In the hindbrain, the coordinated action of various transcription factors and the mobilization of secreted morphogens demarcate the neuroepithelial territory that will give rise to the cerebellum and specify its neurons and glia. The mouse cerebellar primordium arises between E8.5 and E9.5 from within the metencephalon (Wassef and Joyner, 1997; Zervas et al., 2004). Initially, abutting expression domains of the mutually repressive homeobox genes Orthodenticle homolog $2(\mathrm{Otx} 2)$ and
Gastrulation brain homeobox $2(G b x 2)$ regionalize the midhindbrain boundary (MHB) and form the isthmic organizer (IsO). The IsO secretes Fibroblast growth factor 8 (Fgf8), which is necessary and sufficient for the differentiation of cerebellar cells and the initiation of its gross morphology (reviewed in Zervas et al., 2005). Fgf8 controls cerebellar development through its inductive power and its ability to activate and cooperate with genes such as engrailed 1 (En1), engrailed 2 (En2), as well as the paired box genes Pax2 and Pax5 (reviewed in Sillitoe and Joyner, 2007). Once the cerebellar territory is demarcated, cell lineages are committed in the germinal zones. There are two germinal zones that produce the different cerebellar cell types: the rhombic lip and the ventricular zone. The rhombic lip is located at the dorsal and extreme posterior aspect of the cerebellum. Genetic fate mapping using Atoh1 alleles in mouse showed that the rhombic lip gives rise to all cerebellar glutamatergic neurons including the large projection neurons of the cerebellar nuclei, granule cells, and unipolar brush cells (Wingate, 2001; MacHold and Fishell, 2005; Wang et al., 2005; Englund et al., 2006). The other germinal zone is called the ventricular zone; it lines the base of the fourth 
ventricle. The ventricular zone generates all the GABAergic neurons of the cerebellum including the different classes of interneurons, the inhibitory cerebellar nuclei neurons, and all the Purkinje cells. The GABAergic neurons are specified from progenitors that express the transcription factor-encoding gene Ptf1a (Hoshino et al., 2005; Pascual et al., 2007). However, unique cell identities derive from the patterning of both germinal zones into multiple molecular domains in the rhombic lip (Machold et al., 2007; Chizhikov et al., 2010; Green and Wingate, 2014; Yeung et al., 2014) and the ventricular zone (Chizhikov et al., 2006; Zordan et al., 2008; Lundell et al., 2009; Seto et al., 2014). The mechanism by which the different pools of neuronal progenitors give rise to the distinct cell types of the cerebellum are not fully understood. However, using Purkinje cells as an example, it is estimated that the entire Purkinje cell population in the adult arises from $\sim 100$ to 150 precursors, and their specification occurs at around E7-E8 in mice (Baader and Schilling, 1996; Mathis et al., 1997; Hawkes et al., 1998; Watson et al., 2005). Although it is not clear if Purkinje cell precursors are restricted to different sub-lineages, there is evidence that after differentiation, Purkinje cells become restricted to distinct subsets that fall into the pattern of stripes and zones (Figure 2B; Hawkes and Gravel, 1991; Hawkes and Eisenman, 1997; Oberdick et al., 1998; Armstrong and Hawkes, 2000; Herrup and Kuemerle, 2002; Larouche and Hawkes, 2006; Sillitoe and Joyner, 2007; White and Sillitoe, 2013). The Purkinje cell patterns may guide the development of cerebellar motor and non-motor circuits (Sathyanesan et al., 2019), and disrupting cerebellar patterning could lead to a wide variety of conditions (Reeber et al., 2013). Motor conditions with cerebellar involvement include ataxia, dystonia, and tremor, and non-motor disorders include schizophrenia, Tourette's, and autism spectrum disorders (ASD).

The above discussion on micro- and macroarchitectural development and patterning of the cerebellum through development was almost exclusively carried out in model organisms due to their genetic and experimental tractability. As will be discussed later in the section entitled "An evolutionary perspective of gross cerebellar architecture", the cellular architecture of the cerebellum has been largely conserved across vertebrate evolution. However, there have been important gross adaptations in the cerebellar architecture of primates as compared to the murine cerebellum. Interestingly, the massive expansion of the primate cerebellum has been largely related to widespread increases in surface area due to increased foliation as well as the more focal lateral expansion of the cerebellar hemispheres (Balsters et al., 2010). This has occurred in tandem with increased surface area of the primate dentate nucleus [Figure 2A, inset (Dentate), compare to Figure 2A (Lateral); (Sultan et al., 2010)] as well as the expansion of the primate neocortex (Balsters et al., 2010). The functional implications of these morphologic differences may be alluded to in human cerebellar diseases. As a result, we will now turn to ASD as a model condition to discuss how cerebellar development, particularly at the nexus of genetics, morphogenesis, and circuit wiring, impacts functional outcomes. Subsequently, we highlight the extensive inter-regional connectivity of the cerebellum and how it may explain the pervasive effects of cerebellar disruptions.

\section{THE CEREBELLUM IN HUMAN AFFECTIVE AND COGNITIVE DISEASES}

ASD encompass a broad multi-etiologic domain that converges on a characteristic disruption of normal social behavior with a relative sparing of motor function. The term "autism" was coined in the early parts of the twentieth century by Eugen Bleuler to describe a seeming withdrawal from the outside world into the "self" by schizophrenic patients (Lai et al., 2014). The term was then adapted by Leo Kanner to describe the pediatric developmental condition that today is recognized as ASD, drawing a parallel between the withdrawal into the selfseen in schizophrenia to the inability of ASD patients to relate to others (Kanner, 1943). Since then, a more holistic understanding of autism has come to bear. In terms of symptomatology, this has coincided with the recognition that ASDs encompass a wide variety of phenotypes, which may include significant affective, cognitive, and motor impairments (Lai et al., 2014). Furthermore, there is an equally wide spectrum of etiologies, ranging from single gene disruptions with mendelian inheritance, to heritable non-mendelian disease, to entirely acquired etiologies (Lai et al., 2014). However, even in the cases of ASD with mendelian inheritance, there is a varying degree of penetrance, emphasizing the complex genetic and environmental contributions to the disease presentation. Equally complex are the regions of the brain that could drive the behavioral defects. Here, we will examine the ASDs from the perspective of the cerebellum, which has been implicated extensively in ASD (Fatemi et al., 2012), with recent experimental data further supporting its contribution.

While many brain regions have been found to be disrupted in patients with ASD, one of the most consistent sites of brain pathology in ASD is the cerebellum (Allen, 2005). Furthermore, reduction in the normal number of Purkinje cells was one of the most frequently reported abnormalities in early studies (Bailey et al., 1998; Kemper and Bauman, 1998). However, it has been difficult to determine at which point in development Purkinje cell loss occurs, or how much cell loss must occur in order to contribute to the development of ASD symptoms. It is important to mention at this time the developmental correlation between the cerebellum and ASD such that both the environmental insults and brain injuries that increase risk for ASD indeed occur at the time at which there is a massive expansion of the cerebellum (Wang et al., 2014; Figure 3), namely the third trimester of pregnancy continuing into the early postnatal period. Furthermore, cerebellar injury during this sensitive period confers a significant predisposition to neurocognitive disability, including the development of ASD (Limperopoulos et al., 2007). In fact, the risk conferred by cerebellar injury at birth to development of ASD was up to 36x (Wang et al., 2014).

How do these developmental features relate to the Purkinje cell pathology noted in post-mortem studies of autistic individuals? Several lines of evidence provide circumstantial 


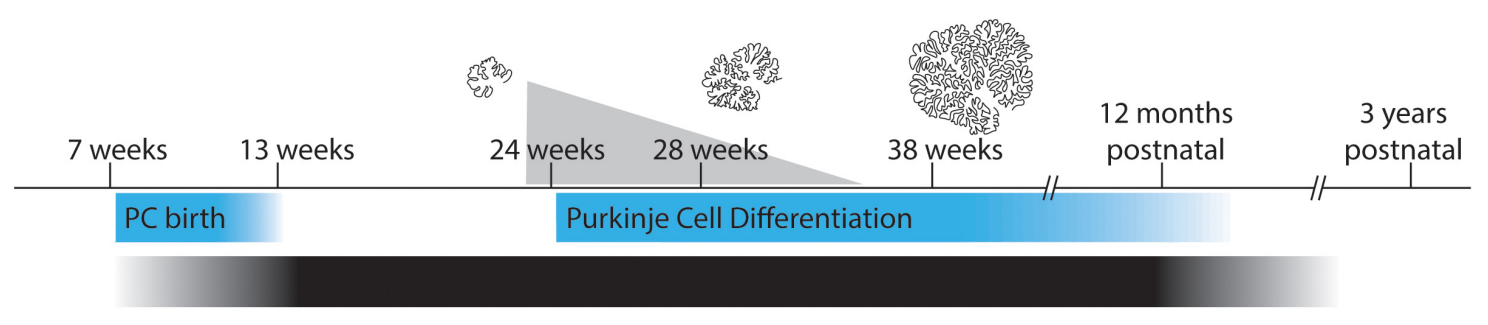

FIGURE 3 | Purkinje cell differentiation, cerebellar expansion, and sensitive periods for developmental disorders. Pictured are various correlations along the time line of gestation through early childhood. Pictured in the upper portion of the figure is a scaled representation of cerebellar size and foliation during gestation. Adapted from Rakic and Sidman (1970) with permission obtained from Wiley Online Library. The superimposed gray triangle represents the incidence of developmental comorbidities associated with premature birth at the corresponding gestational ages. Below the time line in blue are the gestational ages of Purkinje cell birth and differentiation. (Bottom) A gradient showing the time period during which all etiologies of autism are thought to occur. Figure adapted in part from Sathyanesan et al. (2019) with permission obtained from Nature research journals.

evidence for the timing of Purkinje cell dysfunction/death. First, it has been reported that cerebellar stellate and basket cells are preserved in number (Whitney et al., 2009), which is an indication that Purkinje cells likely migrated and settled appropriately after their genesis. Second, in post-mortem studies there is no alteration in the number of inferior olivary neurons, which would be expected to undergo degeneration in the context of denervation from cell death (see related discussion on hypertrophic olivary degeneration; Fatemi et al., 2012), indicating that the Purkinje cell loss occurs prior to the innervation of the Purkinje cells by climbing fiber afferents from the inferior olive in the immediate perinatal period [although, the mode of insult and speed of Purkinje cell loss could affect how their target climbing fibers respond (Rossi and Strata, 1995)]. More recent analysis, however, has called into question how generalized the phenomenon of Purkinje cell loss is in autistic patients, finding that some autistic patients fail to show alterations in Purkinje cell number (Whitney et al., 2008). Given the very wide etiologic spectrum of ASD, perhaps it is not surprising to find that there are manifestations of ASD that do not involve Purkinje cell loss. Nonetheless, available evidence suggests that at least some forms of ASD are associated with loss of Purkinje cells at a critical period after proliferation and migration and prior to completion of circuit wiring of the cerebellum into its mature architecture with functioning connections. It should also be noted though that compensation, both at the genetic and cellular level, could play a role in determining the final number of cells in affected patients.

One of the most striking aspects of ASD is the abnormal social and emotional behavior of affected individuals; a major source of distress in the disease presentation to the parents of an autistic child is the absence of affection. Is there, then, an association between the cerebellum and affect? Recently, in fact, there has been increasing awareness of a role for the cerebellum in affective behavior (Ackermann et al., 1998; Steinlin, 2007). Further, over 40 years ago, while investigating therapies for medically refractory neuropsychiatric illness, it was found that stimulation of the vermis could ameliorate aggressive behavior in patients (Heath, 1977). These findings were functionally extended, showing that modulation of the vermis and the associated fastigial nuclei altered neuronal activity in the deep limbic circuit including in the hippocampus, amygdala, and septal region (Heath et al., 1978). In rats, mechanical disruption of the vermis in pups was found to produce disruption of social and emotional behavior in adulthood (Bobee et al., 2000). Numerous imaging studies in humans have found associations between affect and vermis activation (Tavano et al., 2007; Stoodley and Schmahmann, 2010; Buckner et al., 2011). Specifically, positron emission tomography (PET) and functional magnetic resonance imaging (MRI) studies have found that activation of the vermis is correlated with induced anxiety (Reiman et al., 1989), grief (Gündel et al., 1946), unpleasant emotions (Lane et al., 1997), and depression (Beauregard et al., 1998). Finally, acquired lesions of the vermis in adults have been found to lead to affective disturbances, including emotional lability or pseudobulbar palsy in a patient with a midline cerebellar cyst (Parvizi and Schiffer, 2014) and dysphoria and affective flattening in a patient with isolated cerebellar ischemic stroke (Paulus et al., 2004).

The frank disruption of normal affective behavior is one of the hallmarks of ASD, which heavily implicates vermis involvement as a pathogenic mechanism in cerebellar etiologies of ASD. In fact, a wide range of early studies, looking at post-mortem tissue and using imaging modalities, found disruptions of the vermis in affected individuals. What did these studies reveal? There are findings of hypoplasia of vermal lobules VI and VII (Courchesne et al., 1988), decreased Purkinje cell density in the vermis (Ritvo et al., 1986), mixed hypoplasia and hyperplasia in affected individuals (Courchesne et al., 1994a,b), and overall diminished volume of the vermis (Courchesne et al., 2001). A more recent analysis using volumetric processing of MRI in affected individuals was more equivocal, but did find that overall vermis volume was significantly decreased in ASD patients (Scott et al., 2009).

When looking at gross changes in brain structure, there are a wide array of findings that will not be discussed in great detail, though several key points should be made. First, it is important to note that changes in brain volume are often not stable and can vary significantly over time, based on anatomic location, and based on sex (see discussions in Stanfield et al., 2008; Sussman et al., 2015). In particular, changes in volume have been seen in the neocortex, limbic structures, and the corpus callosum (Stanfield et al., 2008). Additionally, there can 
be a tendency for early expansion of gray and white matter, with later diminishing of volume (Courchesne et al., 2001). As a result, time of study, sex of participant, and IQ of participant are all independent variables that may affect brain volume analysis without consideration of etiology of ASD in that patient. Regarding the cerebellum, volumetric changes have been reported in numerous studies over the last four decades, but it remains unclear how cerebellar white matter versus cerebellar gray matter are affected in ASD, or whether one is a better indicator of pathophysiology over the other.

Nonetheless, the evaluated studies heavily implicate the cerebellum and cerebellar pathology in ASD, however, they do not comment to a great degree on the functional implications of this pathology. For a better understanding from this perspective, a deeper look at structural and functional network integrity in individuals with ASD vis a vis the cerebellum will be helpful.

While the above section focused on the affective changes that characterize ASD, it is important to note that ASD is a pervasive developmental disorder that may have subtle or gross deficits in all domains (Lauritsen, 2013). In correspondence with these observations, aberrant structural and functional connectivity has been observed throughout the cerebellum as well as in the cerebellar efferent pathways that project to the cerebral cortex (D'Mello and Stoodley, 2015). In particular, when controlled for age and IQ, children with ASD showed alterations in cerebellar white matter integrity (Sahyoun et al., 2010). Similar alterations have been in found in the inferior, middle, and superior cerebellar peduncles (SCP), which are the massive white matter afferent and efferent tracts that link the cerebellum with the rest of the nervous system (Catani et al., 2008; Sivaswamy et al., 2010). A caveat to these and the following discussed studies is that the comparisons made were often between individuals with high functioning autism and typically developing individuals due to the required use of imaging modalities in awake, cooperative patients. As a result, whether this level of analysis underestimates the connectivity changes that might be seen in more severe autism, reflects a subset of patients with a fundamentally different etiology of ASD, or is broadly generalizable to all individuals with ASD is unclear.

The imaging studies discussed above used diffusion tensor imaging (DTI) to evaluate white matter structural integrity. Further analysis of cerebellar function in autistic individuals has been conducted using assays of functional connectivity (FC), which uses correlated activity between brain regions in awake patients undergoing functional magnetic resonance imaging (fMRI). Consistent with the structural findings described above, there is abnormal functional connectivity between the cerebellum and the cortex in ASD individuals (Noonan et al., 2009; Khan et al., 2015). However, unexpectedly, both increased and decreased connectivity can be seen, depending on the brain region evaluated. In particular, it was reported there is an increased connectivity between the anterior cerebellum and the sensorimotor areas of the cortex, while there is a decrease in FC between the cerebellar hemispheres and the supramodal, or cognitive, areas of the cortex (Khan et al., 2015). A second study found that the patterns of connectivity in ASD compared to typically developing children were similar, but more extensive in the ASD population (Noonan et al., 2009). Regarding cerebellar gray matter, reductions have been found in both the posterior vermis as well as the cerebellar hemispheres (Stoodley, 2014; Mello et al., 2015).

Linking the findings of reduced cerebellar gray matter, the elaboration of the cerebellum in the perinatal period, and aberrant functional connectivity in ASD, recent transcriptomic profiling of Purkinje cells during development found that there is an enrichment of genes associated with ASD (Clifford et al., 2019). Interestingly, when compared to ASD-associated genes expressed during neocortical development, those in the Purkinje cell cluster were less likely to be associated with comorbid intellectual disability (Clifford et al., 2019). How this finding fits with other analyses linking high functioning, but not low functioning, ASD with cerebellar pathology warrants additional investigation (Noonan et al., 2009; Scott et al., 2009; Khan et al., 2015). In context of the imaging studies described above, as well as earlier studies examining post-mortem tissue, perhaps the variability in cerebellar pathology reflects the wide range of etiologies that contribute to ASD. Nonetheless, the growing body of literature associating the cerebellum with ASD supports the role of normal cerebellar function in all forms of behavior, motor and non-motor alike.

As mentioned previously, cerebellar injury during the period of cerebellar expansion (3rd trimester to birth) confers a significant risk (up to $36 \mathrm{x}$ compared to the general population) for neurocognitive dysfunction and ASD (Limperopoulos et al., 2007; Wang et al., 2014). A recent case report highlighted this association, whereby a child with history of bilateral intrauterine cerebellar stroke underwent neurocognitive evaluation and was diagnosed with ASD (Whiting et al., 2019). Further analysis of patients with congenital cerebellar malformations has revealed consistent non-motor deficits, with these studies demonstrating some degree of anatomic predictability, with vermal malformation showing a predilection for affective dysregulation and hemispheric malformations showing a predilection for executive and linguistic deficits (Tavano et al., 2007). However, in addition to the examination of purely congenital malformations, acquired lesions of the cerebellum, namely resection of low grade posterior fossa tumors, has also been associated with cognitive impairments (Levisohn et al., 2000; Beebe et al., 2005).

The most extensively studied clinical entity related to invasive damage of the cerebellum is posterior fossa syndrome (PFS) related to resection of medulloblastoma. The posterior fossa is the most common location of pediatric brain tumors, and among those tumors in particular, and all pediatric brain tumors generally, medulloblastoma is the most frequent (Pollack, 1994; Northcott et al., 2012). A key component of medulloblastoma management is surgical gross total resection, and the extent of the resection is both a prognostic factor for progression-free survival, but also the development of PFS (Zeltzer et al., 1999; Korah et al., 2010). PFS is a perisurgical constellation of symptoms characterized primarily by mutism, with a wide range of variable accompanying signs including emotional lability, ataxia, hypotonia, and behavioral disturbances (Rekate et al., 1985; Gudrunardottir et al., 2011; 
Lanier and Abrams, 2017). The overt symptoms of mutism, ataxia, and hypotonia often resolve spontaneously in the months following surgery (Gudrunardottir et al., 2011). However, there has recently been an increasing understanding that the occurrence of PFS is an independent predictor of significant long-term neurocognitive dysfunction in a wide variety of domains, including general intellectual ability, processing speed, attention, working memory, and spatial relations - more so than radiation exposure (Palmer et al., 2010; Schreiber et al., 2017). The majority of the literature fails to reach a consensus on the precise etiology of PFS and there are a wide range of theories including both cerebellar and non-cerebellar causes (Lanier and Abrams, 2017). However, as mentioned previously, the non-motor sequelae of resection of low grade tumors from the cerebellar parenchyma implicates the cerebellum in the etiology of PFS, as does the association of PFS with ataxia (Levisohn et al., 2000; Beebe et al., 2005).

Numerous studies have been undertaken to evaluate the changes in cerebellar structure and connectivity in patients who have experienced PFS (Morris et al., 2009; Patay et al., 2014; Avula et al., 2016; Toescu et al., 2018a,b). An evaluation of factors predisposing medulloblastoma patients to development of PFS found that tumor location proximal to the SCP made development of PFS more likely (Morris et al., 2009). This finding was consistent with the subsequent finding that immediate post-operative imaging revealing evidence of disruption of the proximal dentatothalamocortical efferent tracts was a consistent feature in patients with PFS (Morris et al., 2009). Furthermore, compared to patients who did not develop PFS, those who experienced PFS had a consistent alteration in white matter integrity based on DTI of the bilateral SCP, as well as white matter changes in associated non-sensorimotor cortical areas (Morris et al., 2009). The involvement of the proximal dentatothalamocortical pathway due to damage to the SCP was replicated in a subsequent study using conventional MRI image processing [namely fluid-attenuated inversion recovery (FLAIR) and diffusion weighted imaging (DWI]) (Toescu et al., 2018b). This study also found changes in the dentate nucleus in patients with PFS, though this appeared to be a late onset pathology, rather than an acute problem tightly associated with behavioral morbidity (Toescu et al., 2018b). Consistent with PFS being associated with widespread disruption of cerebellar function, multiple studies have found a significant association of PFS with subsequent bilateral hypertrophic degeneration of the olivary nuclei (Patay et al., 2014; Avula et al., 2016). The inferior olive is involved in conveying afferent information to the cerebellum, via climbing fibers, as well as providing feedforward modulation of cerebellar output carried by the dentatorubral afferents. This dentatorubro-olivary loop is referred to as the triangle of Guillain and Molleret. While the debate on the mechanisms involved in the development of PFS are not resolved, there is a significant and growing body of literature implicating disruption of the cerebellar efferent pathways (Toescu et al., 2018a).

Together, the reviewed PFS data offer two salient observations regarding the role of the cerebellum in non-motor function.
First, immediate mechanical damage to the cerebellar efferent pathways leads to a profound disruption of cerebellar function manifesting as ataxia, mutism, and emotional lability, among other clinical findings that comprise clinical PFS. Second, the initial disruption and alteration of cerebellar pathways lead to a second more permanent disruption of function which persists for many years as neurocognitive dysfunction and is reflected in dentato-olivary gray matter degeneration and widespread alterations in cortical white matter structures. This second more permanent alteration, interestingly, manifests almost entirely as neurocognitive rather than motor deficits. Subsequent work aimed at understanding why certain clinical signs and symptoms of PFS resolve while neurocognitive changes persist will be invaluable. Furthermore, a detailed look at how the integrity of the dentato-thalamo-cortical and dentato-rubroolivary pathways contribute to maintaining the integrity of the inferior olive and dentate nucleus, as well as cortical white matter, may be a valuable contribution to the understanding of cerebellar function.

In concurrence with recent consensus discussions (Koziol et al., 2014; Baumann et al., 2015), there is a prominent and longstanding implication of the cerebellum in non-motor function. However, a great deal of the reviewed body of literature are based mainly on correlative analyses. Lacking until recently has been a direct functional understanding of the cerebellum in non-motor domains from the perspective of neurophysiology, cerebellar computations, and anatomic connectivity (Wagner et al., 2017; Watson et al., 2018; Carta et al., 2019; McAfee et al., 2019). Here, we will discuss a few select studies that have used rodent models and various manipulations to understand the nexus of basic and clinical neuroscience of the cerebellum as it relates to cognition functions.

\section{MOUSE MODELS OF CEREBELLAR COGNITIVE DISORDERS}

One of the early genes to be associated with ASD in humans was the homeobox-encoding gene ENGRAILED (EN) (Petit et al., 1995). Even at that time, there was a noted association between ASD and the cerebellum, but the precise nature of how EN was involved in ASD was unclear. Clinically, genome wide association studies continued to solidify the correlation between EN and ASD (Benayed et al., 2005, 2009). To better understand the pathophysiology of EN mutations in ASD, it would be instructive to discuss a series of studies that examined the role of EN during cerebellar patterning. It was initially observed that disruption of EN signaling in mice led to subtle alterations in the gross morphology of cerebellar lobules across the AP axis (Joyner et al., 1991). Subsequent analysis found that more pronounced molecular disruptions of the parasagittal zonal patterning also could be seen in various EN mutant lines (Sillitoe et al., 2008). These studies clearly defined a role for EN signaling along two major cerebellar axes, which could be independent, thus positing that AP and medio-lateral (ML) patterning were independently coordinated. Subsequently, it was found that EN signaling was also required for proper targeting 
of cerebellar mossy fiber afferents (Sillitoe et al., 2010). Building on the original EN association studies (Gharani et al., 2004), a recent report has confirmed the importance of EN signaling in the manifestations of ASD, while also finding that the clinical manifestation of the disease was not tightly associated with the particular polymorphism expressed in a given affected patient (Carratala-Marco et al., 2018). This may not be surprising given the complexity of somatotopy in cerebellar function (Apps and Hawkes, 2009) as well as the finding that multiple molecular mechanisms, not just EN, are required for cerebellar patterning in both the AP and ML axes (Sillitoe and Joyner, 2007; White and Sillitoe, 2013). Further correlations of EN associated disruptions in the mouse cerebellum with particular behavioral outcomes and neurophysiological alterations of the cortex may be informative in fully understanding how the cerebellum mediates non-motor behavior. In this regard, it is interesting that EN is associated with hippocampal and cortical function (Sgadò et al., 2013), and cerebellum-hippocampal and cerebellar-cortical interactions mediate a number of non-motor behaviors (Watson et al., 2018; McAfee et al., 2019).

While the studies of EN commented on mechanisms involved in disrupting the patterning and development of the cerebellum, more recent studies aimed at analyzing how aberrant Purkinje cell function may lead to ASD utilized targeted mutational analysis by producing Purkinje cell specific tuberous sclerosis complex (TSC) mouse models. TSC is an autosomal dominant disorder comprised of mutations in two genes, TSC1 or TSC2, which results in aberrant signaling in the mechanistic target of rapamycin (mTOR) pathway. mTOR is a key pathway involved in protein synthesis, cell proliferation, and cell growth (Sundberg and Sahin, 2015). In addition to epilepsy and complications to tuber formation throughout the body, approximately $50 \%$ of TSC patients meet the criteria for diagnosis of ASD, with a substantial portion of others suffering more subtle neuropsychiatric disturbances (Sundberg and Sahin, 2015; Gipson and Johnston, 2017). Though a previous study linked cerebellar tuber formation to the development of ASD (Weber et al., 2000), more recent efforts have been made to investigate how Purkinje cell function is specifically disrupted through targeted knock-out of TSC1 in Purkinje cells (Tsai et al., 2012; Stoodley et al., 2018). Initial analysis showed that when TSC1 is knocked out of Purkinje cells, there are substantial morphological and neurophysiological changes in Purkinje cells (Tsai et al., 2012). These changes were sufficient to cause behavioral anomalies consistent with what is observed in patients with ASD, including aberrant social interactions, increased repetitive behaviors, and changes in vocalizations (Tsai et al., 2012). Subsequent studies showed that genetically altering TSC1 in vivo also induced structural connectivity defects within cortical areas that have been suspected to be dysfunctional in patients with ASD (Stoodley et al., 2018). These studies were among the first to mechanistically link Purkinje cell dysfunction with specific neurobehavioral outcomes in ASD and support the interesting hypothesis that dysfunction in cerebellar computations, that are perhaps localized to specific lobules such as right CrusI/II, could lead to motor as well as cognitive dysfunction.
The social motivation hypothesis in ASD extends on the findings of altered affective behavior in these patients by positing that the aberrant social interaction is due to inability to appropriately assign reward to social interactions (Dawson et al., 2004; Dawson and Webb, 2010). In fact, Purkinje cell function has been directly linked to prefrontal cortical dopamine release, which could be rescued with direct stimulation of the cerebellar nuclei, bypassing Purkinje cell output (Mittleman et al., 2008). Recently, this cerebellar control over the reward circuitry has been tied to direct connectivity between the cerebellar nuclei and the ventral tegmental area (VTA), a canonical reward center, in the mouse (Carta et al., 2019). Strikingly, modulation of cerebellar connectivity to the VTA was sufficient to alter social behavior in the mouse (Carta et al., 2019). This work points to a surprising level of non-canonical network connectivity that may provide key insight into the role of the cerebellum in ASD and other neuropsychiatric disorders in which abnormal reward response to social interactions is thought to play a role in disease manifestation.

\section{INTERREGIONAL CONNECTIVITY AND THE CEREBELLUM}

The preceding discussion, which emphasizes that contribution of the cerebellum to cognitive processes, may give the unwanted impression that the cerebellum operates as a regulator of cognitive processes to the exclusion of motor function. This, however, is likely not the case. In fact, the integral role of the cerebellum to motor function is canon (Manto et al., 2012; Lang et al., 2017). Rather, the implication of the above discussion is that the cerebellum may actually serve to regulate distributed cortical function via extensive interregional connectivity to nearly all areas of the neocortex (Caligiore et al., 2017; Bostan and Strick, 2018; Miterko et al., 2018; Diedrichsen et al., 2019), whereby diseases with primarily, though not exclusive, cognitive morbidity such as ASD and PFS may have significant cerebellar involvement. With this in mind, the concluding portions of the review will cover evidence supporting a central role for the cerebellum in distributed cortical function, including anatomical, functional, and evolutionary perspectives.

Over 125 years ago, one of the early debates in neuroscience included the discussion of localizationism championed by Charcot in opposition to a proto-network formulation positing distant effects to local lesions championed by Brown-Sequard (Carrera and Tononi, 2014). The latter theory was reformulated as diaschisis by von Monakow, a concept that included the idea that focal lesions led to distant physiologic and clinical effects that could evolve over time (Carrera and Tononi, 2014). This concept was difficult to validate until the advent of more advanced imaging that could assay brain metabolism after brain lesions (Raichle et al., 1975; Phelps et al., 1979). In fact, one of the earliest radiographic examples of diaschisis was found in the cerebellum with an entity described as crossed cerebellar diaschisis, in which hypometabolism is observed in cerebellar hemispheres contralateral to a supratentorial lesion (Baron et al., 1981). Since 
that time, clinical correlation to this phenomenon has been made including a case report in which there was persistent alterations in cerebellar activity after contralateral basal ganglia infarct (Di Piero et al., 1990), a case series showing that in $20 \%$ of patients with thalamic infarct there was associated hypoperfusion of the contralateral cerebellum (Förster et al., 2014), and finally an intriguing case report in which a childhood lesion of the cerebellum corresponded to alterations in contralateral cortical hemispheric function that was compensated by the ipsilateral cortex during performance of a motor task (Nakahachi et al., 2015). The concept of diaschisis is inextricably linked to the concept of distributed network formation, or interregional connectivity.

Original conceptualizations of cerebro-cerebellar connectivity regarding cerebellar functional output to the cerebrum were viewed as being restricted to the motor cortex (Allen and Tsukahara, 1974). Over the years, however, our understanding of the connectivity between the cerebellum and cortical structures has expanded immensely to include extensive mono-, di-, and multi-synaptic projections to and from nearly the entire neocortex, thalamus, and basal ganglia (Schmahmann and Pandya, 1993; Caligiore et al., 2017; Shinoda et al., 2017; Kelly and Strick, 2018). Functionally, this organizational structure has expanded to include direct functional correlations between the cerebellum and cerebral cortical structures. While basal gangliacortical loops and cerebello-cortical loops had previously been thought to be distinct, evidence emerged for tight anatomical and functional connectivity between the cerebellum and basal ganglia (Chen et al., 2014). Furthermore it has been shown that Purkinje cell activity can reflect oscillatory activity of pre-frontal cortical neurons (McAfee et al., 2019) and that cortical motor learning tightly correlates to granule cell activity (Wagner et al., 2019). The latter two studies reflect intimate bidirectional correlations between the cerebellum and cortex, such that the primary cells receiving cerebral afferents, the granule cells, and the primary modulators of cerebellar efferent signaling, the Purkinje cells, are both implicated in supporting cerebral cortical activity. In fact, almost the entire neocortex has now been mapped into functional domains across the cerebellar cortex (Brissenden et al., 2016; King et al., 2019).

In the setting of human disease, two canonical movement disorders, Parkinson's disease (PD) and essential tremor (ET), serve as a clinical counterpart to the changing understanding of the role of the cerebellum in distributed cortical network function. While previously thought of as a motor systems disease, PD has emerged as a syndrome encompassing a wide variety of etiologies with symptoms across behavioral domains (Jankovic, 2008; Michel et al., 2016). Similarly, ET, once defined as a benign tremor disorder, has increasingly been associated with non-motor symptoms (Bologna et al., 2019) and may herald more pervasive neurodegenerative disease (Laroia and Louis, 2011; Tarakad and Jankovic, 2018). In particular, patients suffering from either disease, PD or ET, are predisposed to depressive mood changes, sleep disruptions, and cognitive impairments (Puertas-Martín et al., 2016). These symptoms are generally associated with disturbed integrity of prefrontal networks (Puertas-Martín et al., 2016). Interestingly, in these diseases pathologic changes can be found in the cerebellum (Quattrone et al., 2008; Wu and Hallett, 2013; Dyke et al., 2017; Piccinin et al., 2017). Though the precise etiologies of both diseases remain cryptic, the described cerebellar involvement only furthers the notion of intimate connections across broad cortical domains. Moving forward, studies involving functional connectivity in patients suffering from various forms of each disease may help to better understand the contribution of the cerebellum to prefrontal network integrity and function.

That the cerebellum is involved in cortical networks is well grounded in evidence, as described above. However, there is an argument to be made that the cerebellum is actually a crucial node in these networks and is necessary for their structural and functional integrity; this is a claim that is central to the concept of diaschisis. Some evidence to support this claim is as follows: As described in brief on the topic of PFS, requirement of ongoing cerebellar neurotransmission to the survival of olivary neurons has been demonstrated (Ogawa et al., 2010; Patay et al., 2014; Konno et al., 2016; Sabat et al., 2016; Wang et al., 2019). In this case, the disruption of a node (dentate) in the tripartite dentatorubro-olivary network leads to the transsynaptic degeneration of a second node (olivary) (Sabat et al., 2016). Other examples of degeneration over longer anatomical distances exist, however. In the case of epilepsy, which is thought to be driven primarily by neocortical structures, cerebellar atrophy is a common finding (Hermann et al., 2005; Kros et al., 2015; Allen et al., 2019). This leads to speculation as to whether cerebellar volume changes in certain etiologies of ASD reflect network disruption in addition to those with primary cerebellar pathogenesis (see above discussion).

Finally, recent clinical and model organism studies have begun to demonstrate efficacy of cerebellar stimulation in motor recovery after ischemic stroke, leveraging the newfound understanding of inter-regional connectivity and its role in supporting the integrity of cortical networks (Wessel and Hummel, 2018; Miterko et al., 2019). In rodents, several studies have demonstrated improved motor recovery using cerebellar stimulation after induced cerebral ischemia (Cooperrider et al., 2014; Shah et al., 2017; Chan et al., 2018). Mechanistically, this cerebellar stimulation has been linked to perilesional plasticity, neurogenesis, and neuroprotection via upregulation of telomerase at the site of ischemia (Cooperrider et al., 2014; Chan et al., 2018; Zhang et al., 2019). How does the extensive interregional connectivity of the cerebellum suggested by diaschisis and neurologic disease relate to the role of the cerebellum in complex behavior including cognition?

A central tenet of neuroscience has long placed the expansion of the primate neocortex as the cornerstone for the evolution of intelligence. However, as reviewed, experimental and observational studies define a crucial role for the cerebellum in neocortical network function and even the maintenance of cortical network integrity. In fact, comparative evolutionary studies complete this perspective and position the cerebellum as a key brain region that enables behavioral specialization and drives cortical network complexity across vertebrate lineages. The following section will review the arguments that cerebellum may be a permissive component for the evolution of behavioral complexity in vertebrates. 


\section{AN EVOLUTIONARY PERSPECTIVE OF GROSS CEREBELLAR ARCHITECTURE: IMPLICATIONS ON BEHAVIOR}

In the first half of the twentieth century, Olaf Larsell characterized and developed the nomenclature of the cerebellar fissures and lobules, recognizing the gross conservation of the structure of the cerebellum from birds through mammals (Larsell, 1937, 1948 , 1952). Subsequent work has identified the presence of the cerebellum as a discrete brain structure in all jawed vertebrates, or gnathostomes (Nieuwenhuys et al., 1998; Butts et al., 2011), based on conserved cellular patterning and shared developmental origins (Chaplin et al., 2010). This finding marks the cerebellum as a prominent feature of vertebrate nervous system evolution, as jawless vertebrates (agnatha) comprise only a small portion of all vertebrate species. As described below, the cerebellum displays interesting characteristics that position it as a key player in the diversification of behavior in vertebrates (Montgomery et al., 2012).

\section{A Digression on the Evolutionary Origins of the Cerebellum}

Among species within the infraphylum gnathostoma, there is a wide range of cerebellar morphologic variation, ranging from the flat sheet found in amphibians to the ornate, foliated cerebellum of birds and mammals (Figure 4A; Butts et al., 2011). In clades more closely related to mammals, certain aspects of the gross structure of cerebellum are conserved including a midline vermis and rostrocaudally oriented transverse zones. In mammals and birds there are generally four conserved transverse zones, which are described as anterior (AZ), central (CZ), posterior (PZ), and nodular (NZ) (Ozol et al., 1999; Armstrong and Hawkes, 2000). In birds, there is an additional zone referred to as the lingular zone (LZ) (Marzban et al., 2010). The identity of zones is based heavily on the molecular patterning of markers such as Zebrin II.

As mentioned, over the course of vertebrate evolution, the appearance of the cerebellum coincides with the development of the jaw (Striedter, 2005; Montgomery et al., 2012). As would be expected, the cerebellum did not appear de novo, but rather seems to have an antecedent in the cerebellum-like octavolateralis nuclei of the agnatha, which are present in the jawless, cerebellumlacking lamprey as well as the in the jawed, cerebellumcontaining chondrichthyans (cartilaginous fishes) (Bell, 2002; Montgomery et al., 2012). The octavolaterlis nuclei have a grossly conserved molecular layer in common with the cerebellum, while lacking Purkinje cells and climbing fiber input; functionally, they seem to operate as purely sensory organs, with particular importance in the mechano- and electro-sensory systems (Yopak and Montgomery, 2008; Montgomery et al., 2012). Once the cerebellum evolved in the jawed vertebrates, its expansion has been correlated to the convergent evolution of complex behaviors across vertebrate phylogeny, as will be detailed below.

Despite the early divergence of the cartilaginous fishes in the vertebrate lineage, the principle that the cerebellum and the telencephalon scale in tandem with increases in brain sizes holds for this clade (Yopak and Montgomery, 2008; Yopak et al., 2010). While more in depth studies, which are technically impractical in these animals, would be required to make direct correlations to specific behaviors in the cartilaginous fishes, there does seem to be a correlation between relative cerebellar size and foliation with environmental enrichment (increased in reef dwelling as compared to deep water species) (Yopak et al., 2010). An interesting speculation that arises from this apparent consistency in brain scaling is that the presence of the cerebellum has been a permissive step for the evolution of complex behavior in vertebrates, and that the correlated relative expansion of the telencephalon with the cerebellum is the material evidence of this cooperation.

The idea that the cerebellum is tightly involved with behavioral specializations in individual species has been more closely studied in animals in which ethologically relevant behavior is tractable to scientific analyses. In particular, both birds and mammals have been evaluated in depth in this regard. Particular species of birds are unique among non-mammalian species as having been found to have a wide variety of apparent higher cognitive function, including tool manufacture, object permanence, and theory of mind (Emery and Clayton, 2004; Güntürkün and Bugnyar, 2016). As described previously in the discussion regarding chondrichthyan brain evolution, a relative expansion of the telencephalon and cerebellum also accompanies increasing behavioral complexity in birds (Gutiérrez-Ibáñez et al., 2018). Furthermore, in bird species with higher cognitive function (crows and parrots) there is a greater cerebellar surface area, which takes into account the folding of the cerebellum (Sultan and Glickstein, 2007).

An interesting contrast between birds and mammals is that while they both have an allometric expansion of the telencephalon and cerebellum, it is only the cerebellum that maintains homologous micro and macrostructure (GutiérrezIbáñez et al., 2018). In fact, birds lack key aspects of the cerebral cortex, which is seen by many as the hallmark of primate cognition (Güntürkün and Bugnyar, 2016). Interestingly, the bird telencephalon connects to the cerebellum via a unique midbrain nucleus, the medial spiriform nucleus, rather than the pontine nuclei as seen in mammals (Gutiérrez-Ibáñez et al., 2018). This observation provides surprising context to the discussion in that the evolution of higher cognition in bird species is convergent on the level of broad network formation, yet nonetheless has adapted the cerebellum as a crucial component of information processing through analogous rather than homologous midbrain nuclei.

\section{The Mammalian Cerebellum and Expansion of the Neocortex}

The hallmark of the mammalian cerebellum is the development of cerebellar hemispheres and the associated development of 10 anterior to posteriorly oriented lobules (Larsell, 1967). Despite almost universally comprising less than $20 \%$ of the total brain mass ( $\sim 10 \%$ in humans) the cerebellum houses well over half of the total neurons ( $\sim 80 \%$ in humans) in the mammalian brain (Herculano-Houzel et al., 2015). Furthermore, the cerebellum has expanded nearly in proportion to neocortical expansion in higher primates (Smaers, 2014). Even in non-primate mammals, the 


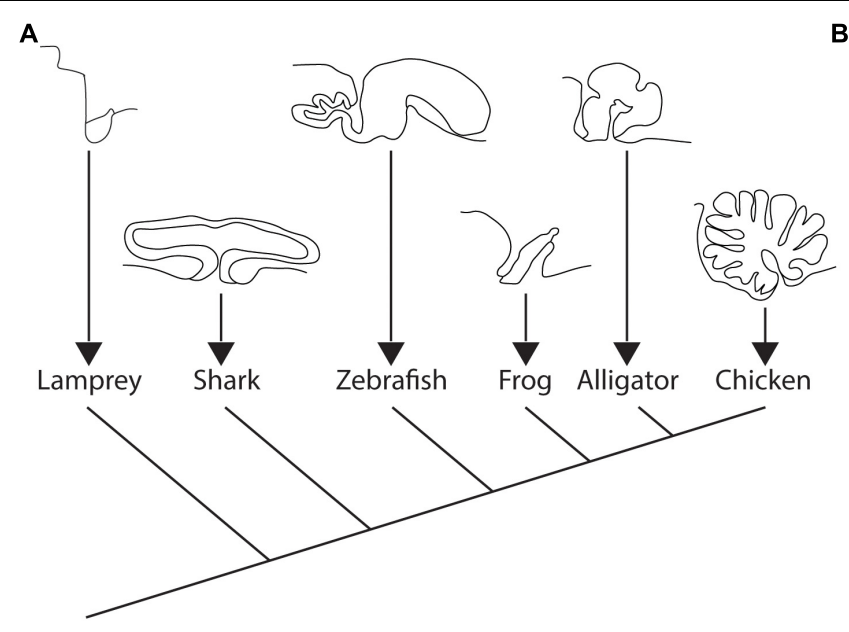

B

FIGURE 4 | Comparative evolution of the cerebellum. (A) Sagittal view of cerebellum and cerebellum-like structures across vertebrates, including a sagittal view of the octavolateralis of the lamprey. Adapted from Butts et al. (2011) with permission obtained from SpringerLink. (B) Examples of the posterior cerebella of three species (Bottlenose Dolphin, Sea Lion, Chimpanzee) that display vocal production learning and a single mammal (White Tailed Deer) that does not. Figure inspired by Smaers et al. (2018) but independently processed directly from Brainmuseum.org (Welker et al., 2019) use was as per open source published guidelines for both eLife and Brainmuseum.org, respectively.

cerebellar hemispheres demonstrate greater relative expansion in those species that display vocal production learning (Smaers et al., 2018), an assay that serves as a proxy to gauge higher order learning in non-primate species (Janik and Slater, 2000). It is interesting to note that the regional hemispheric expansion is not uniform across species, but rather conforms to the nature of the specialization that the animal uses in its behavior.

One of the more in depth studies on cerebellar specializations in mammals, murine and primate species excluded, comes from the thorough molecular patterning analysis of the star nosed mole by Marzban et al. (2015). The authors undertook this analysis to test the hypothesis that the cerebellar machinery adapts to accommodate specializations that define an animal's way of life. Consistent with this hypothesis, the cerebellar lobules receiving visual input (those in the central zone) are diminished while those receiving inputs from the trigeminal nucleus ( $\mathrm{PZ}$ CrusI/II), which is the nucleus that receives mechanosensory information from the "star", are expanded. Similar domain specific hemispheric expansion is seen in the mammals that have been characterized as having vocal production learning (VPL) (Figure 4B): primates, pinnipeds (fin footed mammals e.g., seals), toothed whales, and elephants (Smaers et al., 2018), although in the latter three more detailed analysis is needed. A final evolutionary observation of the mammalian cerebellum in regards to behavioral specialization that ought to be noted is the presence of a lingular-like zone in lobule I of bats, or microchiroptera (Kim J.Y. et al., 2009; Marzban et al., 2015), which was previously noted not in mammalian but avian cerebellum. It is interesting to speculate on whether this is indicative of another example of convergent evolution, in this case regarding flight, for which the cerebellum is part of the neural substrate.

When considering cognition, higher primates occupy a unique position in that we have insight based on self-reflection while also being able to pull from human disease and primate models to better understand the neural basis of cognition. There is essentially universal agreement that the neocortex plays a central role in the development of higher cognition in humans and higher primates (Rakic, 2009). More recently, evidence from evolutionary analyses have implicated cerebellar expansion as a correlated phenomenon that parallels the expansion of the neocortex in both higher primates, generally, but especially so in humans (Barton and Venditti, 2014). Interestingly, the expansion of the cerebellum in humans correlates with an increase in the number of cerebellar neurons (HerculanoHouzel et al., 2015), while the expansion of the neocortex is correlated with an increase in cortical white matter (Zhang and Sejnowski, 2002; Wang et al., 2008). These correlative studies do not independently comment on function, but perhaps do suggest that increased cortical connectivity and cerebellar information processing are critical components of the higher primate nervous system. Theories on the selective pressures that have driven the evolution of the higher primate CNS are by nature speculative but almost universally implicate the necessity of motor planning requiring the integration visuospatial and motor commands, as is required in ambulation and brachiation, as a pretext to the subsequent development of tool use, extractive foraging, and syntactical language development (Ackermann, 2008; Byrne and Bates, 2010; Londei et al., 2010; Fitch, 2011). This interpretation would necessitate that the cerebellar nuclei, which link the cerebellar cortex to the telencephalon, underwent elaboration in tandem with the expansion of the neocortex and cerebellum itself. Indeed, this seems to be the case. There has been a specific trend toward increasing size of the lateral cerebellar nuclei in primates with a specific and marked increase in the dentate, especially in the ventral portion (Matano and Hirasaki, 1997; Matano, 2001). Detailed analysis of the expansion of the dentate revealed that the 
increased volume in fact reflected an increase in the surface area of the dentate gray matter (Sultan et al., 2010). Furthermore, there are differences in the cytology of the nuclei when comparing the dorsal to the ventral dentate (Tellmann et al., 2015), the latter of which has projections to associative areas including the prefrontal and posterior parietal cortices via the thalamus (Dum and Strick, 2006). This finding was recently confirmed in humans using associative probability mapping and correlations with volumetric analyses of post-mortem brain tissue (Tellmann et al., 2015).

Despite the canonical belief that the cerebellum was a brain region devoted primarily to motor learning, coordination, and execution, the above described body of literature reflects the more recent understanding that the cerebellum is a critical component of coordinated and integrated cortical function across domains. Furthermore, cerebellar expansion accompanies increasingly complex behavior across jawed vertebrates and may in fact be thought of as a necessary component of higher cognitive function, at least as defined by one cognitive parameter (VPL). Open questions remain regarding the nature of the computations performed, how universal these functions are across domains, and how they specifically work to form what we consider to be normal cognitive function (Diedrichsen et al., 2019). Moreover, an increasing body of literature points to the cerebellum as a key node in the formation and function of cortical networks (Caligiore et al., 2017; Bostan and Strick, 2018; Miterko et al., 2018).

\section{CONCLUSION}

This review has sought to provide the basis for the emerging consensus that the cerebellum is not only a passive component of cognitive and affective behavior, but a key neural substrate that

\section{REFERENCES}

Ackermann, H. (2008). Cerebellar contributions to speech production and speech perception: psycholinguistic and neurobiological perspectives. Trends Neurosci. 31, 265-272. doi: 10.1016/j.tins.2008.02.011

Ackermann, H., Wildgruber, D., Daum, I., and Grodd, W. (1998). Does the cerebellum contribute to cognitive aspects of speech production? a functional magnetic resonance imaging (fMRI) study in humans. Neurosci. Lett. 247, 187-190. doi: 10.1016/S0304-3940(98)00328-320

Ahn, A. H., Dziennis, S., Hawkes, R., and Herrup, K. (1994). The cloning of zebrin II reveals its identity with aldolase C. Development 120, 2081-2090.

Allen, G. (2005). The cerebellum in autism. Clin. Neuropsychiatry 2, 321-337. doi: 10.1093/acprof:oso/9780195182224.003.0003

Allen, G., and Tsukahara, N. (1974). Cerebrocerebellar. Physiol. Rev. 41, 31-60. doi: 10.1016/s0074-7742(08)60346-3

Allen, L. A., Vos, S. B., Kumar, R., Ogren, J. A., Harper, R. K., Winston, G. P., et al. (2019). Cerebellar, limbic, and midbrain volume alterations in sudden unexpected death in epilepsy. Epilepsia 60, 718-729. doi: 10.1111/epi. 14689

Apps, R., and Hawkes, R. (2009). Cerebellar cortical organization: a one-map hypothesis. Nat. Rev. Neurosci. 10, 670-681. doi: 10.1038/nrn2698

Apps, R., Hawkes, R., Aoki, S., Bengtsson, F., Brown, A. M., Chen, G., et al. (2018). Cerebellar modules and their role as operational cerebellar processing units. Cerebellum 17, 654-682. doi: 10.1007/s12311-018-0952-953

Armstrong, C. L., Chung, S.-H., Armstrong, J. N., Hochgeschwender, U., Jeong, Y.G., and Hawkes, R. (2009). A novel somatostatin-immunoreactive mossy fiber is actively involved in a great number of fundamental behaviors. The repeated adaptation of the computational circuitry and the molecular diversity of the cerebellum in the evolution of complex behavior among vertebrate species offers a compelling argument that the cerebellum is a key component of behavioral specialization. For humans, the fluid continuity between the rich cognitive subtext of our motivations and desires and the remarkable complexity of our motor output cannot be easily disentangled. In the cerebellum, we find a critical neural substrate that has the capacity to seamlessly coordinate these motor and non-motor functions. It is a crucial time in neuroscientific inquiry to expand upon and utilize our knowledge of this structure to better understand how brain networks are formed and how they function in health and disease. This may help to devise interventions to structurally rewire and correct the disruptions that underlie a wide variety of neurologic and neuropsychiatric diseases.

\section{AUTHOR CONTRIBUTIONS}

JG and RS wrote and edited the manuscript.

\section{FUNDING}

RS was supported by the Baylor College of Medicine (BCM) and Texas Children's Hospital, Hamill Foundation, BCM IDDRC Grant U54HD083092 from the Eunice Kennedy Shriver National Institute of Child Health and Human Development (Neuropathology Sub-Core), and National Institute of Neurological Disorders and Stroke (NINDS) grants R01NS089664 and R01NS100874.

pathway asssociated with HSP25-immunoreactive purkinje cell stripes in the mouse cerebellum. J. Comp. Neurol. 517, 524-538. doi: 10.1002/cne.22167

Armstrong, C. L., and Hawkes, R. (2000). Pattern formation in the cerebellar cortex. Biochem. Cell Biol. 78, 551-562. doi: 10.1139/o00-071

Avula, S., Spiteri, M., Kumar, R., Lewis, E., Harave, S., Windridge, D., et al. (2016). Post-operative pediatric cerebellar mutism syndrome and its association with hypertrophic olivary degeneration. Quant. Imaging Med. Surg. 6, 535-544. doi: 10.21037/qims.2016.10.11

Baader, S., and Schilling, K. (1996). Glutamate receptors mediate dynamic regulation of nitric oxide synthase expression in cerebellar granule cells. J. Neurosci. 16, 1440-1449. doi: 10.1523/jneurosci.16-04-01440.1996

Bailey, A., Luthert, P., Dean, A., Harding, B., Janota, I., Montgomery, M., et al. (1998). A clinicopathological study of autism. Brain. doi121, 889-905: 10.1093/brain/121.5.889 doi: 10.1093/brain/121.5.889

Balsters, J. H., Cussans, E., Diedrichsen, J., Phillips, K. A., Preuss, T. M., Rilling, J. K., et al. (2010). Evolution of the cerebellar cortex: the selective expansion of prefrontal-projecting cerebellar lobules. Neuroimage 49, 2045-2052. doi: 10.1016/j.neuroimage.2009.10.045

Baron, J. C., Bousser, M. G., Comar, D., and Castaigne, P. (1981). Crossed cerebellar diaschisis in human supratentorial brain infarction. Trans. Am. Neurol. Assoc. 105, 459-461.

Barton, R. A., and Venditti, C. (2014). Rapid evolution of the cerebellum in humans and other great apes. Curr. Biol. 24, 2440-2444. doi: 10.1016/j.cub.2014.08.056

Baumann, O., Borra, R. J., Bower, J. M., Cullen, K. E., Habas, C., Ivry, R. B., et al. (2015). Consensus paper: the role of the cerebellum in perceptual processes. Cerebellum 14, 197-220. doi: 10.1007/s12311-014-0627-627 
Beauregard, M., Leroux, J. M., Bergman, S., Arzoumanian, Y., Beaudoin, G., Bourgouin, P., et al. (1998). The functional neuroanatomy of major depression: an fMRI study using an emotional activation paradigm. Neuroreport 9, 32533258. doi: 10.1097/00001756-199810050-199810022

Beckinghausen, J., and Sillitoe, R. V. (2019). Insights into cerebellar development and connectivity. Neurosci. Lett. 688, 2-13. doi: 10.1016/j.neulet.2018.05.013

Beebe, D. W., Ris, M. D., Armstrong, F. D., Fontanesi, J., Mulhern, R., Holmes, E., et al. (2005). Cognitive and adaptive outcome in low-grade pediatric cerebellar astrocytomas: evidence of diminished cognitive and adaptive functioning in national collaborative research studies (CCG 9891/POG 9130). J. Clin. Oncol. 23, 5198-5204. doi: 10.1200/JCO.2005.06.117

Bell, C. C. (2002). Evolution of Cerebellum-Like Structures. Brain. Behav. Evol. 59, 312-326. doi: 10.1159/000063567

Benayed, R., Choi, J., Matteson, P. G., Gharani, N., Kamdar, S., Brzustowicz, L. M., et al. (2009). Autism-associated haplotype affects the regulation of the homeobox gene, ENGRAILED 2. Biol. Psychiatry 66, 911-917. doi: 10.1016/j. biopsych.2009.05.027

Benayed, R., Gharani, N., Rossman, I., Mancuso, V., Lazar, G., Kamdar, S., et al. (2005). Support for the homeobox transcription factor gene ENGRAILED 2 as an autism spectrum disorder susceptibility locus. Am. J. Hum. Genet. 77, 851-868. doi: 10.1086/497705

Bobee, S., Mariette, E., Tremblay-Leveau, H., and Caston, J. (2000). Effects of early midline cerebellar lesion on cognitive and emotional functions in the rat. Behav Brain Res. 112, 107-117. doi: 10.1016/s0166-4328(00)00166-2

Bologna, M., Berardelli, I., Paparella, G., Ferrazzano, G., Angelini, L., Giustini, P., et al. (2019). Tremor distribution and the variable clinical presentation of essential tremor. Cerebellum doi: 10.1007/s12311-019-01070-0 [Epub ahead of print].

Bostan, A. C., and Strick, P. L. (2018). The basal ganglia and the cerebellum: nodes in an integrated network. Nat. Rev. Neurosci. 19, 338-350. doi: 10.1038/s41583018-0002-7

Braak, E., and Braak, H. (1993). The new monodendritic neuronal type within the adult human cerebellar granule cell layer shows calretinin-immunoreactivity. Neurosci. Lett. 154, 199-202. doi: 10.1016/0304-3940(93)90206-Z

Brasnjo, G., and Otis, T. S. (2001). Neuronal glutamate transporters control activation of postsynaptic metabotropic glutamate receptors and influence cerebellar long-term depression. Neuron 31, 607-616. doi: 10.1016/s08966273(01)00377-4

Brissenden, J. A., Levin, E. J., Osher, D. E., Halko, M. A., and Somers, D. C. (2016). Functional evidence for a cerebellar node of the dorsal attention network. J. Neurosci. 36, 6083-6096. doi: 10.1523/jneurosci.0344-16.2016

Brochu, G., Maler, L., and Hawkes, R. (1990). Zebrin II: a polypeptide antigen expressed selectively by purkinje cells reveals compartments in rat and fish cerebellum. J. Comp. Neurol. 291, 538-552. doi: 10.1002/cne.902910405

Buckner, R. L., Krienen, F. M., Castellanos, A., Diaz, J., and Yeo, B. T. T. (2011). The organization of the human cerebellum estimated by intrinsic functional connectivity. J. Neurophysiol. 106, 1125-1165. doi: 10.1152/jn.00338.2011

Buffo, A., and Rossi, F. (2013). Origin, lineage and function of cerebellar glia. Prog. Neurobiol. 109, 42-63. doi: 10.1016/j.pneurobio.2013.08.001

Butts, T., Chaplin, N., and Wingate, R. J. T. (2011). Can clues from evolution unlock the molecular development of the cerebellum? Mol. Neurobiol. 43, 67-76. doi: 10.1007/s12035-010-8160-8162

Byrne, R. W., and Bates, L. A. (2010). Primate social cognition: uniquely primate, uniquely social, or just unique? Neuron 65, 815-830. doi: 10.1016/j.neuron. 2010.03.010

Caligiore, D., Pezzulo, G., Baldassarre, G., Bostan, A. C., Strick, P. L., Doya, K., et al. (2017). Consensus paper: towards a systems-level view of cerebellar function: the interplay between cerebellum, basal ganglia, and cortex. Cerebellum 16, 203-229. doi: 10.1007/s12311-016-0763-763

Carratala-Marco, F., Andreo-Lillo, P., Martinez-Morga, M., Escamez-Martínez, T., Botella-López, A., Bueno, C., et al. (2018). Clinical phenotypes associated to engrailed 2 gene alterations in a series of neuropediatric patients. Front. Neuroanat. 12:61. doi: 10.3389/fnana.2018.00061

Carrera, E., and Tononi, G. (2014). Diaschisis: past, present, future. Brain 137, 2408-2422. doi: 10.1093/brain/awu101

Carta, I., Chen, C. H., Schott, A. L., Dorizan, S., and Khodakhah, K. (2019). Cerebellar modulation of the reward circuitry and social behavior. Science 363:eaav0581. doi: 10.1126/science.aav0581
Catani, M., Jones, D. K., Daly, E., Embiricos, N., Deeley, Q., Pugliese, L., et al. (2008). Altered cerebellar feedback projections in Asperger syndrome. Neuroimage 41, 1184-1191. doi: 10.1016/j.neuroimage.2008.03.041

Cerminara, N. L., and Apps, R. (2011). Behavioural significance of cerebellar modules. Cerebellum 10, 484-494. doi: 10.1007/s12311-010-0209-202

Cerminara, N. L., Lang, E. J., Sillitoe, R. V., and Apps, R. (2015). Redefining the cerebellar cortex as an assembly of non-uniform Purkinje cell microcircuits. Nat. Rev. Neurosci. 16, 79-93. doi: 10.1038/nrn3886

Chan, H. H., Cooperrider, J., Chen, Z., Gale, J. T., Baker, K. B., Wathen, C. A., et al. (2018). Lateral cerebellar nucleus stimulation has selective effects on glutamatergic and gabaergic perilesional neurogenesis after cortical ischemia in the rodent model. Clin. Neurosurg. 83, 1057-1067. doi: 10.1093/neuros/nyx473

Chaplin, N., Tendeng, C., and Wingate, R. J. T. (2010). Absence of an external germinal layer in zebrafish and shark reveals a distinct, anamniote ground plan of cerebellum development. J. Neurosci. 30, 3048-3057. doi: 10.1523/jneurosci. 6201-09.2010

Chen, C. H., Fremont, R., Arteaga-Bracho, E. E., and Khodakhah, K. (2014). Short latency cerebellar modulation of the basal ganglia. Nat. Neurosci. 17, 1767-1775. doi: $10.1038 / \mathrm{nn} .3868$

Chizhikov, V. V., Lindgren, A. G., Currle, D. S., Rose, M. F., Monuki, E. S., and Millen, K. J. (2006). The roof plate regulates cerebellar cell-type specification and proliferation. Development 133, 2793-2804. doi: 10.1242/dev.02441

Chizhikov, V. V., Lindgren, A. G., Mishima, Y., Roberts, R. W., Aldinger, K. A., Miesegaes, G. R., et al. (2010). Lmxla regulates fates and location of cells originating from the cerebellar rhombic lip and telencephalic cortical hem. Proc. Natl. Acad. Sci. U.S.A. 107, 10725-10730. doi: 10.1073/pnas.0910786107

Clifford, H., Dulneva, A., Ponting, C. P., Haerty, W., and Becker, E. B. E. (2019). A gene expression signature in developing Purkinje cells predicts autism and intellectual disability co-morbidity status. Sci. Rep. 9:485. doi: 10.1038/s41598018-37284-37281

Consalez, G. G., and Hawkes, R. (2013). The compartmental restriction of cerebellar interneurons. Front. Neural. Circ. 6:123. doi: 10.3389/fncir.2012. 00123

Cooperrider, J., Furmaga, H., Plow, E., Park, H.-J., Chen, Z., Kidd, G., et al. (2014). Chronic deep cerebellar stimulation promotes long-term potentiation, microstructural plasticity, and reorganization of perilesional cortical representation in a rodent model. J. Neurosci. 34, 9040-9050. doi: 10.1523/jneurosci.0953-14.2014

Courchesne, E., Karns, C. M., Davis, H. R., Ziccardi, R., Carper, R. A., Tigue, Z. D., et al. (2001). Unusual brain growth patterns in early life in patients with autistic disorder: an MRI study. Neurology 57, 245-254. doi: 10.1212/WNL.57.2.245

Courchesne, E., Saitoh, O., Townsend, J. P., Yeung-Courchesne, R., Press, G. A., Lincoln, A. J., et al. (1994a). Cerebellar hypoplasia and hyperplasia in infantile autism. Lancet 343, 63-64. doi: 10.1016/S0140-6736(94)90923-90927

Courchesne, E., Townsend, J., and Saitoh, O. (1994b). The brain in infantile autism: posterior fossa structures are abnormal. Neurology 44, 214-223.

Courchesne, E., Yeung-Courchesne, R., Press, G. A., Hesselink, J., and Jernigan, T. (1988). Hypoplasia of cerebellar vermal lobules VI and VII in autism. N. Engl. J. Med. 318, 1349-1354. doi: 10.1056/nejm198805263182102

Courville, J., Faraco-Cantin, F., and Diakiw, N. (1974). A functionally important feature of the distribution of the olivo-cerebellar climbing fibers. Can. J. Physiol. Pharmacol. 52, 1212-1217. doi: 10.1139/y74- 159

Dawson, G., Toth, K., Abbott, R., Osterling, J., Munson, J., Estes, A., et al. (2004). Early social attention impairments in autism: social orienting, joint attention, and attention to distress. Dev. Psychol. 40, 271-283. doi: 10.1037/0012-1649.40. 2.271

Dawson, G., and Webb, S. J. (2010). Developmental neuropsychology understanding the nature of face processing impairment in autism: insights from behavioral and electrophysiological studies. Dev. Neuropsychol. 5641, 37-41. doi: 10.1207/s15326942dn2703

Dehnes, Y., Chaudhry, F. A., Ullensvang, K., Lehre, K. P., Storm-Mathisen, J., and Danbolt, N. C. (1998). The glutamate transporter EAAT4 in rat cerebellar Purkinje cells: a glutamate-gated chloride channel concentrated near the synapse in parts of the dendritic membrane facing astroglia. J. Neurosci. 18, 3606-3619. doi: 10.1523/jneurosci.18-10-03606.1998

Di Piero, V., Chollet, F., Dolan, R. J., Thomas, D. J., and Frackowiak, R. (1990). The functional nature of cerebellar diaschisis. Stroke 21, 1365-1369. doi: 10.1161/01. STR.21.9.1365 
Diedrichsen, J., King, M., Hernandez-castillo, C., Sereno, M., and Ivry, R. B. (2019). Universal transform or multiple functionality? understanding the contribution of the human cerebellum across task domains. Neuron 102, 918-928. doi: 10.1016/j.neuron.2019.04.021

D'Mello, A. M., and Stoodley, C. J. (2015). Cerebro-cerebellar circuits in autism spectrum disorder. Front. Neurosci. 9:408. doi: 10.3389/fnins.2015.00408

Dum, R. P., and Strick, P. L. (2006). An unfolded map of the cerebellar dentate nucleus and its projections to the cerebral cortex. J. Neurophysiol. 89, 634-639. doi: 10.1152/jn.00626.2002

Dyke, J. P., Cameron, E., Hernandez, N., Dydak, U., and Louis, E. D. (2017). Gray matter density loss in essential tremor: a lobule by lobule analysis of the cerebellum. Cerebellum Ataxias 4:10

Emery, N., and Clayton, N. (2004). The mentality of crows: convergent evolution of intelligence in corvids and apes. Science 306, 1903-1907. doi: 10.1126/science. 1098410

Englund, C., Kowalczyk, T., Daza, R. A. M., Dagan, A., Lau, C., Rose, M. F., et al. (2006). Unipolar brush cells of the cerebellum are produced in the rhombic lip and migrate through developing white matter. J. Neurosci. 26, 9184-9195. doi: 10.1523/jneurosci.1610-06.2006

Fatemi, S. H., Aldinger, K. A., Ashwood, P., Bauman, M. L., Blaha, C. D., Blatt, G. J., et al. (2012). Consensus paper: pathological role of the cerebellum in Autism. Cerebellum 11, 777-807. doi: 10.1007/s12311-012-0355-359

Fitch, W. T. (2011). The evolution of syntax: an exaptationist perspective. Front. Evol. Neurosci. 3:9. doi: 10.3389/fnevo.2011.00009

Förster, A., Kerl, H. U., Goerlitz, J., Wenz, H., and Groden, C. (2014). Crossed cerebellar diaschisis in acute isolated thalamic infarction detected by dynamic susceptibility contrast perfusion MRI. PLoS One 9:e88044. doi: 10.1371/journal. pone. 0088044

Gharani, N., Benayed, R., Mancuso, V., Brzustowicz, L. M., and Millonig, J. H. (2004). Association of the homeobox transcription factor, ENGRAILED 2, 3 , with autism spectrum disorder. Mol. Psychiatry 9, 474-484. doi: 10.1038/sj.mp. 4001498

Gebre, S. A., Reeber, S. L., and Sillitoe, R. V. (2012). Parasagittal compartmentation of cerebellar mossy fibers as revealed by the patterned expression of vesicular glutamate transporters VGLUT1 and VGLUT2. Brain Struct. Funct. 217, 165180. doi: 10.1007/s00429-011-0339-334

Gipson, T. T., and Johnston, M. V. (2017). New insights into the pathogenesis and prevention of tuberous sclerosis-associated neuropsychiatric disorders (TAND). F1000Research 6:859. doi: 10.12688/f1000research.11110.1

Glickstein, M., and Voogd, J. (1995). Lodewijk Bolk and the comparative anatomy of the cerebellum. Trends Neurosci. 18, 206-210. doi: 10.1016/0166-2236(95) 93903-B

Goertzen, A., and Veh, R. W. (2018). Fañanas cells-the forgotten cerebellar glia cell type: immunocytochemistry reveals two potassium channel-related polypeptides, Kv2.2 and Calsenilin (KChIP3) as potential marker proteins. Glia 66, 2200-2208. doi: 10.1002/glia.23478

Green, M. J., and Wingate, R. J. T. (2014). Developmental origins of diversity in cerebellar output nuclei. Neural Dev. 9, 2-9. doi: 10.1186/1749-8104-9-1

Gudrunardottir, T., Sehested, A., Juhler, M., and Schmiegelow, K. (2011). Cerebellar mutism: review of the literature. Child's Nerv. Syst. 27, 355-363. doi: 10.1007/s00381-010-1328-1322

Guell, X., Gabrieli, J. D. E., and Schmahmann, J. D. (2018). Embodied cognition and the cerebellum: perspectives from the dysmetria of thought and the universal cerebellar transform theories. Cortex 100, 140-148. doi: 10.1016/j. cortex.2017.07.005

Gündel, H., Littrell, L., Carolyn Fort, B., and Richard Lane, B. D. (1946). Functional neuroanatomy of grief: an fMRI study. Artic. Am. J. Psychiatry 16011, 19461953. doi: 10.1176/appi.ajp.160.11.1946

Güntürkün, O., and Bugnyar, T. (2016). Cognition without cortex. Trends Cogn. Sci. 20, 291-303. doi: 10.1016/j.tics.2016.02.001

Guo, C., Witter, L., Rudolph, S., Elliott, H. L., Ennis, K. A., and Regehr, W. G. (2016). Purkinje cells directly inhibit granule cells in specialized regions of the cerebellar cortex. Neuron 91, 1330-1341. doi: 10.1016/j.neuron.2016. 08.011

Gutiérrez-Ibáñez, C., Iwaniuk, A. N., and Wylie, D. R. (2018). Parrots have evolved a primate-like telencephalic-midbrain-cerebellar circuit. Sci. Rep. 8:9960. doi: 10.1038/s41598-018-28301-28304
Hawkes, R., and Eisenman, L. M. (1997). Stripes and zones: the origins of regionalization of the adult cerebellum. Persp. Dev. Neurobiol. 5, 95-105.

Hawkes, R., Faulkner-Jones, B., Tam, P., and Tan, S. S. (1998). Pattern formation in the cerebellum of murine embryonic stem cell chimeras. Eur. J. Neurosci. 10, 790-793. doi: 10.1046/j.1460-9568.1998.00085.x

Hawkes, R., and Gravel, C. (1991). The modular cerebellum. Prog. Neurobiol. 36, 309-327. doi: 10.1016/0301-0082(91)90004-K

Hawkes, R., and Leclerc, N. (1987). Antigenic map of the rat cerebellar cortex: the distribution of parasagittal bands as revealed by monoclonal anti-purkinje cell antibody mabQ113. J. Comp. Neurol. 256, 29-41. doi: 10.1002/cne.902560104

Heath, R. (1977). Modulation of emotion with a brain pacemaker. treatment for intractable psychiatric illness. J. Nerv. Ment. Dis. 165, 300-317. doi: 10.1097/ 00005053-197711000-00002

Heath, R. G., Dempesy, C. W., Fontana, C. J., and Myers, W. A. (1978). Cerebellar stimulation: effects on septal region, hippocampus, and amygdala of cats and rats. Biol. Psychiatry 13, 501-529.

Herculano-Houzel, S., Catania, K., Manger, P. R., and Kaas, J. H. (2015). Mammalian brains are made of these: a dataset of the numbers and densities of neuronal and nonneuronal cells in the brain of glires, primates, scandentia, eulipotyphlans, afrotherians and artiodactyls, and their relationship with body mass. Brain. Behav. Evol. 86, 145-163. doi: 10.1159/000437413

Hermann, B. P., Bayless, K., Hansen, R., Parrish, J., and Seidenberg, M. (2005). Cerebellar atrophy in temporal lobe epilepsy. Epilepsy Behav. 7, 279-287. doi: 10.1016/j.yebeh.2005.05.022

Herndon, R. M. (1963). The fine structure of the Purkinje cell. J. Cell Biol. 18, 167-180. doi: 10.1083/jcb.18.1.167

Herrup, K., and Kuemerle, B. (2002). the compartmentalization of the cerebellum. Annu. Rev. Neurosci. 20, 61-90. doi: 10.1146/annurev.neuro.20.1.61

Horn, K. M., Pong, M., and Gibson, A. R. (2010). Functional relations of cerebellar modules of the cat. J. Neurosci. 30, 9411-9423. doi: 10.1523/JNEUROSCI.044010.2010

Hoshino, M., Nakamura, S., Mori, K., Kawauchi, T., Terao, M., Nishimura, Y. V., et al. (2005). Ptfla, a bHLH transcriptional gene, defines GABAergic neuronal fates in cerebellum. Neuron 47, 201-213. doi: 10.1016/j.neuron.2005.06.007

Janik, V. M., and Slater, P. J. B. (2000). The different roles of social learning in vocal communication. Anim. Behav. 60, 1-11. doi: 10.1006/anbe.2000.1410

Jankovic, J. (2008). Parkinson's disease: clinical features and diagnosis. J. Neurol. Neurosurg. Physiatry. 79, 368-376. doi: 10.1136/jnnp.2007.131045

Joyner, A. L., Herrup, K., Auerbach, B. A., Davis, C. A., and Rossant, J. (1991). Subtle cerebellar phenotype in mice homozygous for a targeted deletion of the En-2 homeobox. Science 251, 1239-1243. doi: 10.1126/science.1672471

Kanner, L. (1943). Autistic disturbances of affective contact. Nervous child. Nerv. Child 2, 217-250. doi: 10.1111/fwb.12896

Kelly, R. M., and Strick, P. L. (2018). Cerebellar loops with motor cortex and prefrontal cortex of a nonhuman primate. J. Neurosci. 23, 8432-8444. doi: 10.1523/jneurosci.23-23-08432.2003

Kemper, T. L., and Bauman, M. (1998). Neuropathology of infantile Autism. J. Neuropathol. Exp. Neurol. 57, 645-652. doi: 10.1097/00005072-199807000199807001

Khan, A. J., Nair, A., Keown, C. L., Datko, M. C., Lincoln, A. J., and Müller, R. A. (2015). Cerebro-cerebellar resting-state functional connectivity in children and adolescents with autism spectrum disorder. Biol. Psychiatry 78, 625-634. doi: 10.1016/j.biopsych.2015.03.024

Kim, C. H., Oh, S. H., Lee, J. H., Chang, S. O., Kim, J., and Kim, S. J. (2012). Lobule-specific membrane excitability of cerebellar Purkinje cells. J. Physiol. 590, 273-288. doi: 10.1113/jphysiol.2011. 221846

Kim, J. Y., Marzban, H., Chung, S.-H., Watanabe, M., Eisenman, L. M., and Hawkes, R. (2009). Purkinje cell compartmentation of the cerebellum of microchiropteran bats. J. Comp. Neurol. 517, 193-209. doi: 10.1002/cne.22147

Kim, Y. S., Shin, J. H., Hall, F. S., and Linden, D. J. (2009). Dopamine signaling is required for depolarization-induced slow current in cerebellar purkinje cells. J. Neurosci. 29, 8530-8538. doi: 10.1523/jneurosci.0468-09.2009

King, M., Hernandez-Castillo, C. R., Poldrack, R. A., Ivry, R. B., and Diedrichsen, J. (2019). Functional boundaries in the human cerebellum revealed by a multidomain task battery. Nat. Neurosci. 22, 1371-1378. doi: 10.1038/s41593-0190436-x 
Konno, T., Broderick, D. F., Tacik, P., Caviness, J. N., and Wszolek, Z. K. (2016). Hypertrophic olivary degeneration: a clinico-radiologic study. Park. Relat. Disord. 28, 36-40. doi: 10.1016/j.parkreldis.2016.04.008

Korah, M. P., Esiashvili, N., Mazewski, C. M., Hudgins, R. J., Tighiouart, M., Janss, A. J., et al. (2010). Incidence, risks, and sequelae of posterior fossa syndrome in pediatric medulloblastoma. Int. J. Radiat. Oncol. Biol. Phys. 77, 106-112. doi: 10.1016/j.ijrobp.2009.04.058

Koziol, L. F., Budding, D., Andreasen, N., D’Arrigo, S., Bulgheroni, S., Imamizu, H., et al. (2014). Consensus paper: the cerebellum's role in movement and cognition. Cerebellum 13, 151-177. doi: 10.1007/s12311-013-0511-x

Kros, L., Eelkman Rooda, O. H. J., De Zeeuw, C. I., and Hoebeek, F. E. (2015). Controlling cerebellar output to treat refractory epilepsy. Trends Neurosci. 38, 789-799. doi: 10.1016/j.tins.2015.10.002

Lai, M.-C., Lombardo, M. V., and Baron-Cohen, S. (2014). Autism. Lancet 383, 896-910. doi: 10.1007/978-1-4939-3474-4-91

Lane, R. D., Reiman, E. M., Bradley, M. M., Lang, P. J., Ahern, G. L., Davidson, R. J., et al. (1997). Neuroanatomical correlates of pleasant and unpleasant emotion. Neuropsychologia 35, 1437-1444. doi: 10.1016/S0028-3932(97)00070-75

Lang, E. J., Apps, R., Bengtsson, F., Cerminara, N. L., De Zeeuw, C. I., Ebner, T. J., et al. (2017). The roles of the olivocerebellar pathway in motor learning and motor control. a consensus paper. Cerebellum 16, 230-252. doi: 10.1007/ s12311-016-0787-788

Lanier, J. C., and Abrams, A. N. (2017). Posterior fossa syndrome: review of the behavioral and emotional aspects in pediatric cancer patients. Cancer 123, 551-559. doi: 10.1002/cncr.30238

Laroia, H., and Louis, E. D. (2011). Association between essential tremor and other neurodegenerative diseases: what is the epidemiological evidence? Neuroepidemiology 37, 1-10. doi: 10.1159/000328866

Larouche, M., and Hawkes, R. (2006). From clusters to stripes: the developmental origins of adult cerebellar compartmentation. Cerebellum 5, 77-88. doi: $10.1080 / 14734220600804668$

Larsell, O. (1937). The cerebellum: a review and interpretation. Arch. Neurol. Psychiatry 38, 580-607.

Larsell, O. (1948). The development and subdivisions of the cerebellum of birds. J. Comp. Neurol. 89, 123-189. doi: 10.1002/cne.900890204

Larsell, O. (1952). The morphogenesis and adult pattern of the lobules and fissures ofthe cerebellum ofthe white rat. J. Comp. Neurol. Comp. Neurol. 97, 281-356. doi: $10.1002 / \mathrm{cne} .900970204$

Larsell, O. (1967). The comparative anatomy and histology of the cerebellum: from monotremes through apes. Arch Neurol. 24:94. doi: 10.1001/archneur.1971. 00480310122014

Lauritsen, M. B. (2013). Autism spectrum disorder. Eur. Child Adolesc. Psychiatry 22, S37-S42. doi: 10.1016/B978-0-12-800685-6.00016-13

Levisohn, L., Cronin-golomb, A., and Schmahmann, J. D. (2000). Neuropsychological consequences of cerebellar tumour resection in children Cerebellar cognitive affective syndrome in a paediatric population. Brain 123, 1041-1050. doi: 10.1093/brain/123.5.1041

Limperopoulos, C., Bassan, H., Gauvreau, K., Robertson, R. L., Sullivan, N. R., Benson, C. B., et al. (2007). Does cerebellar injury in premature infants contribute to the high prevalence of long-term cognitive, learning, and behavioral disability in survivors? Pediatrics 120, 584-593. doi: 10.1542/peds. 2007-1041

Londei, A., D’Ausilio, A., Basso, D., Sestieri, C., Del Gratta, C., Romani, G. L., et al. (2010). Sensory-motor brain network connectivity for speech comprehension. Hum. Brain Mapp. 31, 567-580. doi: 10.1002/hbm.20888

Lundell, T. G., Zhou, Q., and Doughty, M. L. (2009). Neurogenin1 expression in cell lineages of the cerebellar cortex in embryonic and postnatal mice. Dev. Dyn. 238, 3310-3325. doi: $10.1002 /$ dvdy.22165

MacHold, R., and Fishell, G. (2005). Math1 is expressed in temporally discrete pools of cerebellar rhombic-lip neural progenitors. Neuron 48, 17-24. doi: 10.1016/j.neuron.2005.08.028

Machold, R. P., Kittell, D. J., and Fishell, G. J. (2007). Antagonism between Notch and bone morphogenetic protein receptor signaling regulates neurogenesis in the cerebellar rhombic lip. Neural Dev. 2:5. doi: 10.1186/1749-8104-2-5

Manto, M., Bower, J. M., Conforto, A. B., Delgado-García, J. M., Da Guarda, S. N. F., Gerwig, M., et al. (2012). Consensus paper: roles of the cerebellum in motor control-the diversity of ideas on cerebellar involvement in movement. Cerebellum 11, 457-487. doi: 10.1007/s12311-011-0331-339
Mariën, P., Ackermann, H., Adamaszek, M., Barwood, C. H. S., Beaton, A., Desmond, J., et al. (2014). Consensus paper: language and the cerebellum: an ongoing enigma. Cerebellum 13, 386-410. doi: 10.1007/s12311-0130540-545

Marzban, H., Chung, S.-H., Pezhouh, M. K., Feirabend, H., Watanabe, M., Voogd, J., et al. (2010). Antigenic compartmentation of the cerebellar cortex in the chicken (Gallus domesticus). J. Comp. Neurol. 518, 2221-2239. doi: 10.1002/ cne. 22328

Marzban, H., Hoy, N., Buchok, M., Catania, K. C., and Hawkes, R. (2015). Compartmentation of the cerebellar cortex: adaptation to lifestyle in the starnosed mole condylura cristata. Cerebellum 14, 106-118. doi: 10.1007/s12311014-0618-618

Matano, S. (2001). Brief communication: proportions of the ventral half of the cerebellar dentate nucleus in humans and great apes. Am. J. Phys. Anthropol. 114, 163-165. doi: 10.1002/1096-8644(200102)114:2<163::aid-ajpa1016>3.3. co;2-6

Matano, S., and Hirasaki, E. (1997). Volumetric comparisons in the cerebellar complex of anthropoids, with special reference to locomotor types. Am. J. Phys. Anthropol. 103, 173-183. doi: 10.1002/(sici)1096-8644(199706)103:2<173::aidajpa4>3.0.co;2-v

Mateos, J. M., Osorio, A., Azkue, J. J., Benítez, R., Elezgarai, I., Bilbao, A., et al. (2001). Parasagittal compartmentalization of the metabotropic glutamate receptor mGluR1b in the cerebellar cortex. Eur. J. Anat. 5, 15-21.

Mathis, L., Bonnerot, C., Puelles, L., and Nicolas, J. F. (1997). Retrospective clonal analysis of the cerebellum using genetic laacZ/lacZ mouse mosaics. Development 124, 4089-4104.

Matsushita, M., and Wang, C. L. (1987). Projection pattern of vestibulocerebellar fibers in the anterior vermis of the cat: an anterograde wheat germ agglutininhorseradish peroxidase study. Neurosci. Lett. 74, 25-30. doi: 10.1016/03043940(87)90045-90040

McAfee, S. S., Liu, Y., Sillitoe, R. V., and Heck, D. H. (2019). Cerebellar lobulus simplex and crus i differentially represent phase and phase difference of prefrontal cortical and hippocampal oscillations. Cell Rep. 27, 2328-2334. doi: 10.1016/j.celrep.2019.04.085

Mello, A. M. D., Crocetti, D., Mostofsky, S. H., and Stoodley, C. J. (2015). NeuroImage: clinical cerebellar gray matter and lobular volumes correlate with core autism symptoms. YNICL 7, 631-639. doi: 10.1016/j.nicl.2015. 02.007

Michel, P. P., Hirsch, E. C., and Hunot, S. (2016). Understanding dopaminergic cell death pathways in parkinson disease. Neuron 90, 675-691. doi: 10.1016/j. neuron.2016.03.038

Miterko, L. N., Baker, K. B., Beckinghausen, J., Bradnam, L. V., Cheng, M. Y., Cooperrider, J., et al. (2019). Consensus paper: experimental neurostimulation of the cerebellum. Cerebellum doi: 10.1007/s12311-019-01041-5 [Epub ahead of print].

Miterko, L. N., Lackey, E. P., Heck, D. H., and Sillitoe, R. V. (2018). Shaping diversity into the brain's form and function. Front. Neural Circ. 12:83. doi: 10.3389/fncir.2018.00083

Mittleman, G., Goldowitz, D., Heck, D. H., and Blaha, C. D. (2008). Cerebellar modulation of frontal cortex dopamine efflux in mice: relevance to autism and schizophrenia. Synapse 62, 544-550. doi: 10.1002/syn.20525

Montgomery, J. C., Bodznick, D., and Yopak, K. E. (2012). The cerebellum and cerebellum-like structures of cartilaginous fishes. Brain. Behav. Evol. 80, 152-165. doi: 10.1159/000339868

Morris, E. B., Phillips, N. S., Laningham, F. H., Patay, Z., Gajjar, A., Wallace, D., et al. (2009). Proximal dentatothalamocortical tract involvement in posterior fossa syndrome. Brain 132, 3087-3095. doi: 10.1093/brain/ awp241

Mugnaini, E., and Floris, A. (1994). The unipolar brush cell: a neglected neuron of the mammalian cerebellar cortex. J. Comp. Neurol. 339, 174-180. doi: 10.1002/ cne. 903390203

Nakahachi, T., Ishii, R., Canuet, L., and Iwase, M. (2015). Implied functional crossed cerebello-cerebral diaschisis and interhemispheric compensation during hand grasping more than 20 years after unilateral cerebellar injury in early childhood. Cerebellum Ataxias 2:15. doi: 10.1186/s40673-0150032-30

Nieuwenhuys, R., ten Donkelaar, H. J., and Nicholson, C. (1998). The Central Nervous System of Vertebrates. Berlin: Springer. 
Noonan, S. K., Haist, F., and Müller, R. A. (2009). Aberrant functional connectivity in autism: evidence from low-frequency BOLD signal fluctuations. Brain Res. 1262, 48-63. doi: 10.1016/j.brainres.2008.12.076

Northcott, P. A., Jones, D. T. W., Kool, M., Robinson, G. W., Gilbertson, R. J., Cho, Y. J., et al. (2012). Medulloblastomics: the end of the beginning. Nat. Rev. Cancer 12, 818-834. doi: $10.1038 / \mathrm{nrc} 3410$

Oberdick, J., Baader, S., and Schilling, K. (1998). From zebra stripes to postal zones: deciphering patterns of gene expression in the cerebellum. Trends Neurosci. 21, 383-390. doi: 10.1016/s0166-2236(98)01325-3

Oberdick, J., and Sillitoe, R. V. (2011). Cerebellar zones: history, development, and function. Cerebellum 10, 301-306. doi: 10.1007/s12311-011-0306-x

Ogawa, K., Mizutani, T., Uehara, K., Minami, M., Suzuki, Y., and Uchihara, T. (2010). Pathological study of pseudohypertrophy of the inferior olivary nucleus. Neuropathology 30, 15-23. doi: 10.1111/j.1440-1789.2009.0 1033. $\mathrm{x}$

Ozol, K., Hayden, J. M., Oberdick, J., and Hawkes, R. (1999). Transverse zones in the vermis of the mouse cerebellum. J. Comp. Neurol. 412, 95-111. doi: 10.1002/(sici)1096-9861(19990913)412:1<95::aid-cne7>3.3.co;2-p

Palmer, S. L., Hassall, T., Evankovich, K., Mabbott, D. J., Bonner, M., Deluca, C., et al. (2010). Neurocognitive outcome 12 months following cerebellar mutism syndrome in pediatric patients with medulloblastoma. Neuro. Oncol. 12, 1311-1317. doi: 10.1093/neuonc/noq094

Parvizi, J., and Schiffer, R. (2014). Exaggerated crying and tremor with a cerebellar cyst. J. Neuropsychiatry Clin. Neurosci. 19, 187-190. doi: 10.1176/jnp.2007.19.2. 187

Pascual, M., Abasolo, I., Mingorance-Le Meur, A., Martinez, A., Del Rio, J. A., Wright, C. V. E., et al. (2007). Cerebellar GABAergic progenitors adopt an external granule cell-like phenotype in the absence of Ptfla transcription factor expression. Proc. Natl. Acad. Sci. U.S.A. 104, 5193-5198. doi: 10.1073/pnas. 0605699104

Patay, Z., Enterkin, J., Harreld, J. H., Yuan, Y., Löbel, U., Rumboldt, Z., et al. (2014). MR imaging evaluation of inferior olivary nuclei: comparison of postoperative subjects with and without posterior fossa syndrome. Am. J. Neuroradiol. 35, 797-802. doi: 10.3174/ajnr.A3762

Paukert, M., Huang, Y. H., Tanaka, K., Rothstein, J. D., and Bergles, D. E. (2010). Zones of enhanced glutamate release from climbing fibers in the mammalian cerebellum. J. Neurosci. 30, 7290-7299. doi: 10.1523/jneurosci.5118-09.2010

Paulus, K. S., Magnano, I., Conti, M., Galistu, P., D’Onofrio, M., Satta, W., et al. (2004). Pure post-stroke cerebellar cognitive affective syndrome: a case report. Neurol. Sci. 25, 220-224. doi: 10.1007/s10072-004-0325-321

Perciavalle, V., Apps, R., Bracha, V., Delgado-García, J. M., Gibson, A. R., Leggio, M., et al. (2013). Consensus paper: current views on the role of cerebellar interpositus nucleus in movement control and emotion. Cerebellum 12, 738-757. doi: 10.1007/s12311-013-0464-460

Petit, E., Hérault, J., Martineau, J., Perrot, A., Barthélémy, C., Hameury, L., et al. (1995). Association study with two markers of a human homeogene in infantile autism. J. Med. Genet. 32, 269-274. doi: 10.1136/jmg.32.4.269

Phelps, M. E., Huang, S. C., Hoffman, E. J., Selin, C., Sokoloff, L., and Kuhl, D. E. (1979). Tomographic measurement of local cerebral glucose metabolic rate in humans with (F-18)2-fluoro-2-deoxy-D-glucose: validation of method. Ann. Neurol. 6, 371-388. doi: 10.1002/ana.410060502

Piccinin, C. C., Campos, L. S., Guimarães, R. P., Piovesana, L. G., dos Santos, M. C. A., Azevedo, P. C., et al. (2017). Differential pattern of cerebellar atrophy in tremor-predominant and akinetic/rigidity-predominant parkinson's disease. Cerebellum 16, 623-628. doi: 10.1007/s12311-016-0834-835

Pijpers, A., Apps, R., Pardoe, J., Voogd, J., and Ruigrok, T. J. H. (2006). Precise spatial relationships between mossy fibers and climbing fibers in rat cerebellar cortical zones. J. Neurosci. 26, 12067-12080. doi: 10.1523/jneurosci.2905-06. 2006

Pollack, I. (1994). Brain tumors in children. N. Engl. J. Med. 331, 1500-1507.

Puertas-Martín, V., Villarejo-Galende, A., Fernández-Guinea, S., Romero, J. P., Louis, E. D., and Benito-León, J. (2016). A comparison study of cognitive and neuropsychiatric features of essential tremor and parkinson's disease. Tremor Other Hyperkinet. Mov. 6:431. doi: 10.7916/D86H4HRN

Quattrone, A., Cerasa, A., Messina, D., Nicoletti, G., Hagberg, G. E., Lemieux, L., et al. (2008). Essential head tremor is associated with cerebellar vermis atrophy: a volumetric and voxel-based morphometry MR imaging study. Am. J. Neuroradiol. 29, 1692-1697. doi: 10.3174/ajnr.A1190
Raichle, M., Larson, K., Phelps, M., Grubb, R. L., Welch, M., and Ter-Pogossian, M. (1975). In vivo measurement of brain glucose transport and metabolism employing glucose- -11C. Am. J. Physiol. Content 228, 1936-1948. doi: 10.1152/ ajplegacy.1975.228.6.1936

Rakic, P. (2009). Evolution of the neocortex: a perspective from developmental biology. Nat. Rev. Neurosci. 10, 724-735. doi: 10.1038/nrn2719

Rakic, P., and Sidman, R. L. (1970). Histogenesis of cortical layers in human cerebellum, particularly the lamina dissecans. J. Comp. Neurol. 139, 473-500. doi: $10.1002 /$ cne. 901390407

Reeber, S. L., White, J. J., George-Jones, N. A., and Sillitoe, R. V. (2013). Architecture and development of olivocerebellar circuit topography. Front. Neural. Circ. 6:115. doi: 10.3389/fncir.2012.00115

Reiman, E., Raichle, M., Robins, E., Mintun, M., Fusselman, M., Fox, P., et al. (1989). Neuroanatomical correlates of a lactate-induced anxiety attack. Arch. Gen. Psychiatry 46, 493-500.

Rekate, H. L., Grubb, R. L., Aram, D. M., Hahn, J. F., and Ratcheson, R. A. (1985). Muteness of cerebellar origin. Arch. Neurol. 42, 697-698. doi: 10.1001/archneur. 1985.04060070091023

Ritvo, E., Freeman, B., Scheibel, A., Duong, T., Robinson, H., Guthrie, D., et al. (1986). Lower purkinje cell counts in the cerebella of four autistic subjects: initial findings of the UCLA-NSAC autopsy research report. Am. J. Psychiatry 143, 862-866. doi: 10.1176/ajp.143.7.862

Rossi, F., and Strata, P. (1995). Reciprocal trophic interactions in the adult climbing fibre-purkinje cell system. Prog. Neurobiol. 47, 341-369. doi: 10.1016/03010082(95)00027-5

Ruigrok, T. J. H. (2011). Ins and outs of cerebellar modules. Cerebellum 10, 464-474. doi: 10.1007/s12311-010-0164-y

Sabat, S., Mannering, N., and Agarwal, A. (2016). Hypertrophic olivary degeneration: case series and review of literature. J. Neurol. Sci. 370, 180-186. doi: 10.1016/j.jns.2016.09.055

Sahyoun, C. P., Belliveau, J. W., and Mody, M. (2010). White matter integrity and pictorial reasoning in high-functioning children with autism. Brain Cogn. 73 , 180-188. doi: 10.1016/j.bandc.2010.05.002

Sarna, J. R., Marzban, H., Watanabe, M., and Hawkes, R. (2006). Complementary stripes of phospholipase $\mathrm{C} \beta 3$ and $\mathrm{C} \beta 4$ expression by Purkinje cell subsets in the mouse cerebellum. J. Comp. Neurol. 496, 303-313. doi: 10.1002/cne.20912

Sathyanesan, A., Zhou, J., Scafidi, J., Heck, D. H., Sillitoe, R. V., and Gallo, V. (2019). Emerging connections between cerebellar development, behaviour and complex brain disorders. Nat. Rev. Neurosci. 20, 298-313. doi: 10.1038/s41583019-0152-152

Sawada, K., Fukui, Y., and Hawkes, R. (2008). Spatial distribution of corticotropinreleasing factor immunopositive climbing fibers in the mouse cerebellum: analysis by whole mount immunohistochemistry. Brain Res. 1222, 106-117. doi: 10.1016/j.brainres.2008.05.029

Schmahmann, J. D. (1991). An emerging concept: the cerebellar contribution to higher function. Arch. Neurol. 48, 1178-1187.

Schmahmann, J. D. (2004). Disorders of the cerebellum: ataxia, dysmetria of thought, and the cerebellar cognitive affective syndrome. J. Neuropsychiatry Clin. Neurosci. 16, 367-378. doi: 10.1176/jnp.16.3.367

Schmahmann, J. D., and Pandya, D. N. (1993). Prelunate, occipitotemporal, and parahippocampal projections to the basis pontis in rhesus monkey. J. Comp. Neurol. 337, 94-112. doi: 10.1002/cne.903370107

Schreiber, J. E., Palmer, S. L., Conklin, H. M., Mabbott, D. J., Swain, M. A., Bonner, M. J., et al. (2017). Posterior fossa syndrome and long-term neuropsychological outcomes among children treated for medulloblastoma on a multi-institutional, prospective study. Neuro. Oncol. 19, 1673-1682. doi: 10.1093/neuonc/nox135

Scott, J. A., Schumann, C. M., Goodlin-Jones, B. L., and Amaral, D. G. (2009). A comprehensive volumetric analysis of the cerebellum in children and adolescents with autism spectrum disorder. Autism Res. 2, 246-257. doi: 10.1002 /aur.97

Scott, T. (1963). A unique pattern of localization within the cerebellum. Nature 200:793. doi: 10.1038/200793a 0

Seto, Y., Nakatani, T., Masuyama, N., Taya, S., Kumai, M., Minaki, Y., et al. (2014). Temporal identity transition from Purkinje cell progenitors to GABAergic interneuron progenitors in the cerebellum. Nat. Commun. 5:3337. doi: 10.1038/ ncomms 4337

Sgadò, P., Provenzano, G., Dassi, E., Adami, V., Zunino, G., Genovesi, S., et al. (2013). Transcriptome profiling in engrailed-2 mutant mice reveals common 
molecular pathways associated with autism spectrum disorders. Mol. Autism 4:51. doi: 10.1186/2040-2392-4-51

Shah, A. M., Ishizaka, S., Cheng, M. Y., Wang, E. H., Bautista, A. R., Levy, S., et al. (2017). Optogenetic neuronal stimulation of the lateral cerebellar nucleus promotes persistent functional recovery after stroke. Sci. Rep. 7:46612. doi: $10.1038 /$ srep 46612

Shin, J. H., Kim, Y. S., and Linden, D. J. (2008). Dendritic glutamate release produces autocrine activation of mGluR1 in cerebellar Purkinje cells. Proc. Natl. Acad. Sci. U.S.A. 105, 746-750. doi: 10.1073/pnas.0709407105

Shinoda, Y., Sugiuchi, Y., Futami, T., and Izawa, R. (2017). Axon collaterals of mossy fibers from the pontine nucleus in the cerebellar dentate nucleus. J. Neurophysiol. 67, 547-560. doi: 10.1152/jn.1992.67.3.547

Sillitoe, R. V., and Joyner, A. L. (2007). Morphology, molecular codes, and circuitry produce the three-dimensional complexity of the cerebellum. Annu. Rev. Cell Dev. Biol. 23, 549-577. doi: 10.1146/annurev.cellbio.23.090506.123237

Sillitoe, R. V., Marzban, H., Larouche, M., Zahedi, S., Affanni, J., and Hawkes, R. (2004). Conservation of the architecture of the anterior lobe vermis of the cerebellum across mammalian species. Prog. Brain Res. 148, 283-297. doi: 10.1016/S0079-6123(04)48022-48024

Sillitoe, R. V., Stephen, D., Lao, Z., and Joyner, A. L. (2008). Engrailed homeobox genes determine the organization of purkinje cell sagittal stripe gene expression in the adult cerebellum. J. Neurosci. 28, 12150-12162. doi: 10.1523/jneurosci. 2059-08.2008

Sillitoe, R. V., Vogel, M. W., and Joyner, A. L. (2010). Engrailed homeobox genes regulate establishment of the cerebellar afferent circuit map. J. Neurosci. 30, 10015-10024. doi: 10.1523/jneurosci.0653-10.2010

Sivaswamy, L., Kumar, A., Rajan, D., Behen, M., Muzik, O., Chugani, D., et al. (2010). A diffusion tensor imaging study of the cerebellar pathways in children with autism spectrum disorder. J. Child Neurol. 25, 1223-1231. doi: 10.1177/ 0883073809358765

Smaers, J. B. (2014). Modeling the Evolution of the Cerebellum. From Macroevolution to Function, 1st Edn. Amsterdam: Elsevier.

Smaers, J. B., Turner, A. H., Gómez-Robles, A., and Sherwood, C. C. (2018). A cerebellar substrate for cognition evolved multiple times independently in mammals. eLife 7, e35696. doi: 10.7554/elife.35696

Sotelo, C. (2008). Viewing the cerebellum through the eyes of Ramón Y Cajal. Cerebellum 7, 517-522. doi: 10.1007/s12311-008-0078-70

Sotelo, C., and Alvarado-Mallart, R. M. (1987). Embryonic and adult neurons interact to allow Purkinje cell replacement in mutant cerebellum. Nature 327, 421-423. doi: 10.1038/327421a0

Stanfield, A. C., McIntosh, A. M., Spencer, M. D., Philip, R., Gaur, S., and Lawrie, S. M. (2008). Towards a neuroanatomy of autism: a systematic review and metaanalysis of structural magnetic resonance imaging studies. Eur. Psychiatry 23, 289-299. doi: 10.1016/j.eurpsy.2007.05.006

Steinlin, M. (2007). The cerebellum in cognitive processes: supporting studies in children. Cerebellum 6, 237-241. doi: 10.1080/14734220701344507

Stoodley, C. J. (2014). Distinct regions of the cerebellum show gray matter decreases in autism, ADHD, and developmental dyslexia. Front. Syst. Neurosci. 8:92. doi: $10.3389 /$ fnsys.2014.00092

Stoodley, C. J., D’Mello, A. M., Ellegood, J., Jakkamsetti, V., Liu, P., Nebel, M. B., et al. (2018). Author Correction: altered cerebellar connectivity in autism and cerebellar-mediated rescue of autism-related behaviors in mice (Nature Neuroscience). Nat. Neurosci. 21:1016. doi: 10.1038/s41593-018-0096-92

Stoodley, C. J., and Schmahmann, J. D. (2010). Evidence for topographic organization in the cerebellum of motor control versus cognitive and affective processing. Cortex 46, 831-844. doi: 10.1016/j.cortex.2009.11.008

Striedter, G. F. (2005). Principles of Brain Evolution. Sunderland, MA: Sinauer Associates.

Sugihara, I. (2004). Molecular, topographic, and functional organization of the cerebellar cortex: a study with combined aldolase $\mathrm{C}$ and olivocerebellar labeling. J. Neurosci. 24, 8771-8785. doi: 10.1523/jneurosci.1961-04.2004

Sugihara, I., Wu, H., and Shinoda, Y. (1999). Morphology of single olivocerebellar axons labeled with biotinylated dextran amine in the rat. J. Comp. Neurol. 414, 131-148. doi: 10.1002/(sici)1096-9861(19991115)414:2<131::aid-cnel>3.3.co; $2-6$

Sultan, F., and Glickstein, M. (2007). The cerebellum: comparative and animal studies. Cerebellum 6, 168-176. doi: 10.1080/14734220701332486
Sultan, F., Hamodeh, S., and Baizer, J. S. (2010). The human dentate nucleus: a complex shape untangled. Neuroscience 167, 965-968. doi: 10.1016/j. neuroscience.2010.03.007

Sundberg, M., and Sahin, M. (2015). Cerebellar development and autism spectrum disorder in tuberous sclerosis complex. J. Child Neurol. 30, 1954-1962. doi: $10.1177 / 0883073815600870$

Sussman, D., Leung, R. C., Vogan, V. M., Lee, W., Trelle, S., Lin, S., et al. (2015). The autism puzzle: diffuse but not pervasive neuroanatomical abnormalities in children with ASD. NeuroImage Clin. 8, 170-179. doi: 10.1016/j.nicl.2015.04. 008

Tarakad, A., and Jankovic, J. (2018). Essential tremor and parkinson's disease: exploring the relationship. Tremor Other Hyperkinet. Mov. 8:589. doi: 10.7916/ D8MD0GVR

Tavano, A., Grasso, R., Gagliardi, C., Triulzi, F., Bresolin, N., Fabbro, F., et al. (2007). Disorders of cognitive and affective development in cerebellar malformations. Brain 130, 2646-2660. doi: 10.1093/brain/awm201

Tellmann, S., Bludau, S., Eickhoff, S., Mohlberg, H., Minnerop, M., and Amunts, K. (2015). Cytoarchitectonic mapping of the human brain cerebellar nuclei in stereotaxic space and delineation of their co-activation patterns. Front. Neuroanat. 09:54. doi: 10.3389/fnana.2015.00054

Toescu, S. M., Hales, P. W., Aquilina, K., and Clark, C. A. (2018a). Quantitative MRI in post-operative paediatric cerebellar mutism syndrome. Eur. J. Radiol. 108, 43-51. doi: 10.1016/j.ejrad.2018.09.007

Toescu, S. M., Hettige, S., Phipps, K., Smith, R. P., Haffenden, V., Clark, C., et al. (2018b). Post-operative paediatric cerebellar mutism syndrome: time to move beyond structural MRI. Child's Nerv. Syst. 34, 2249-2257. doi: 10.1007/s00381018-3867-x

Tsai, P. T., Hull, C., Chu, Y., Greene-Colozzi, E., Sadowski, A. R., Leech, J. M., et al. (2012). Autistic-like behaviour and cerebellar dysfunction in Purkinje cell Tsc1 mutant mice. Nature 488, 647-651. doi: 10.1038/nature 11310

van Rossum, J. (1969). Corticonuclear and Corticovestibular Projections of the Cerebellum. An Experimental Investigation of the Anterior Lobe, the Simple Lobule and the Caudal Vermis of the Rabbit. Van Gorcum: Assen

Voogd, J. (2011). Cerebellar zones: a personal history. Cerebellum 10, 334-350. doi: 10.1007/s12311-010-0221-226

Voogd, J., and Glickstein, M. (1998). The anatomy of the cerebellum. Trends Neurosci. 2236, 370-375.

Voogd, J., and Koehler, P. J. (2018). Historic Notes on Anatomic, Physiologic, and Clinical Research on the Cerebellum, 1st Edn. Netherlnd: Elsevier.

Voogd, J., Pardoe, J., Ruigrok, T. J. H., and Apps, R. (2003). The distribution of climbing and mossy fiber collateral branches from the copula pyramidis and the paramedian lobule: congruence of climbing fiber cortical zones and the pattern of zebrin banding within the rat cerebellum. J. Neurosci. 23, 4645-4656. doi: 10.1523/jneurosci.23-11-04645.2003

Wadiche, J. I., and Jahr, C. E. (2005). Patterned expression of Purkinje cell glutamate transporters controls synaptic plasticity. Nat. Neurosci. 8, 1329-1334. doi: $10.1038 / \mathrm{nn} 1539$

Wagner, M. J., Kim, T. H., Kadmon, J., Nguyen, N. D., Ganguli, S., Schnitzer, M. J., et al. (2019). Shared cortex-cerebellum dynamics in the execution and learning of a motor task. Cell 177, 669-682. doi: 10.1016/j.cell.2019. 02.019

Wagner, M. J., Kim, T. H., Savall, J., Schnitzer, M. J., and Luo, L. (2017). Cerebellar granule cells encode the expectation of reward. Nature 544, 96-100. doi: 10.1038 /nature21726

Wang, H., Wang, Y., Wang, R., Li, Y., Wang, P., Li, J., et al. (2019). Hypertrophic olivary degeneration: a comprehensive review focusing on etiology. Brain Res. 1718, 53-63. doi: 10.1016/j.brainres.2019.04.024

Wang, S. S. H., Kloth, A. D., and Badura, A. (2014). The cerebellum, sensitive periods, and autism. Neuron 83, 518-532. doi: 10.1016/j.neuron.2014. 07.016

Wang, S. S.-H., Shultz, J. R., Burish, M. J., Harrison, K. H., Hof, P. R., Towns, L. C., et al. (2008). Functional trade-offs in white matter axonal scaling. J. Neurosci. 28, 4047-4056. doi: 10.1523/jneurosci.5559-05.2008

Wang, V. Y., Rose, M. F., and Zoghbi, H. Y. (2005). Math1 expression redefines the rhombic lip derivatives and reveals novel lineages within the brainstem and cerebellum. Neuron 48, 31-43. doi: 10.1016/j.neuron.2005.08.024 
Wassef, M., and Joyner, A. L. (1997). Early mesencephalon/metencephalon patterning and development of the cerebellum. Perspect. Dev. Neurobiol. 5, 3-16.

Watson, C. M., Pelka, G. J., Radziewic, T., Shahbazian, M. D., Christodoulou, J., Williamson, S. L., et al. (2005). Reduced proportion of purkinje cells expressing paternally derived mutant Mecp2308 allele in female mouse cerebellum is not due to a skewed primary pattern of X-chromosome inactivation. Hum. Mol. Genet. 14, 1851-1861. doi: 10.1093/hmg/ddi191

Watson, T., Obiang, P., Torres-Herraez, A., Wattilliaux, A., Coulon, P., Rochefort, C., et al. (2018). Anatomical and physiological foundations of cerebellohippocampal interactions. bioRxiv

Weber, A. M., Egelhoff, J. C., McKellop, J. M., and Franz, D. N. (2000). Autism and the cerebellum: evidence from tuberous sclerosis. J. Autism Dev. Disord. 30, 511-517. doi: 10.1023/A:1005679108529

Welker, W., Johnson, J. I., and Noe, A. (2019). BrainMuseum.Org. Univ. Wisconsin Michigan State Comp. Mamm. Brain Collect. University of Wisconsin: Madison, WI

Wessel, M. J., and Hummel, F. C. (2018). Non-invasive cerebellar stimulation: a promising approach for stroke recovery? Cerebellum 17, 359-371. doi: 10.1007/ s12311-017-0906-901

White, J. J., and Sillitoe, R. V. (2013). Postnatal development of cerebellar zones revealed by neurofilament heavy chain protein expression. Front. Neuroanat. 7:9. doi: $10.3389 /$ fnana.2013.00009

Whiting, S. E., Carson, A. M., Clark, G. D., and Schwartz, D. D. (2019). Case report of prenatal bilateral cerebellar infarction: implications for social-behavioral functioning. Clin. Neuropsychol. 0, 1-15. doi: 10.1080/13854046.2018.15 63631

Whitney, E. R., Kemper, T. L., Bauman, M. L., Rosene, D. L., and Blatt, G. J. (2008). Cerebellar purkinje cells are reduced in a subpopulation of autistic brains: a stereological experiment using calbindin-D28k. Cerebellum 7, 406-416. doi: 10.1007/s12311-008-0043-y

Whitney, E. R., Kemper, T. L., Rosene, D. L., Bauman, M. L., and Blatt, G. J. (2009). Density of cerebellar basket and stellate cells in autism: evidence for a late developmental loss of purkinje cells. J. Neurosci. Res. 87, 2245-2254. doi: $10.1002 / j n r .22056$

Wingate, R. J. T. (2001). The rhombic lip and early cerebellar development. Curr. Opin. Neurobiol. 11, 82-88. doi: 10.1016/S0959-4388(00)00177-X

Wizeman, J. W., Guo, Q., Wilion, E. M., and Li, J. Y. (2019). Specification of diverse cell types during early neurogenesis of the mouse cerebellum. eLife 8:e42388. doi: $10.7554 /$ elife. 42388

Wu, T., and Hallett, M. (2013). The cerebellum in Parkinson's disease. Brain 136, 696-709. doi: 10.1093/brain/aws360

Xiao, J., Cerminara, N. L., Kotsurovskyy, Y., Aoki, H., Burroughs, A., Wise, A. K., et al. (2014). Systematic regional variations in Purkinje cell spiking patterns. PLoS One 9:e105633. doi: 10.1371/journal.pone.01 05633
Yeung, J., Ha, T. J., Swanson, D. J., Choi, K., Tong, Y., and Goldowitz, D. (2014). Wls provides a new compartmental view of the rhombic lip in mouse cerebellar development. J. Neurosci. 34, 12527-12537. doi: 10.1523/jneurosci.1330-14. 2014

Yopak, K. E., Lisney, T. J., Darlington, R. B., Collin, S. P., Montgomery, J. C., and Finlay, B. L. (2010). A conserved pattern of brain scaling from sharks to primates. Proc. Natl. Acad. Sci. U.S.A. 107, 12946-12951. doi: 10.1073/pnas. 1002195107

Yopak, K. E., and Montgomery, J. C. (2008). Brain organization and specialization in deep-sea chondrichthyans. Brain. Behav. Evol. 71, 287-304. doi: 10.1159/ 000127048

Zeltzer, B. P. M., Boyett, J. M., Finlay, J. L., Albright, A. L., Rorke, L. B., Milstein, J. M., et al. (1999). Metastasis stage, adjuvant treatment, and residual tumor are prognostic factors for medulloblastoma in children: conclusions from the children's cancer group 921 randomized phase III study. J. Clin. Oncol. 17, 832-845.

Zervas, M., Blaess, S., and Joyner, A. L. (2005). Classical embryological studies and modern genetic analysis of midbrain and cerebellum development. Curr. Top. Dev. Biol. 69, 101-138. doi: 10.1016/S0070-2153(05)69005-69009

Zervas, M., Millet, S., Ahn, S., and Joyner, A. L. (2004). Cell behaviors and genetic lineages of the mesencephalon and rhombomere 1. Neuron 43, 345-357. doi: 10.1016/j.neuron.2004.07.010

Zhang, K., and Sejnowski, T. J. (2002). A universal scaling law between gray matter and white matter of cerebral cortex. Proc. Natl. Acad. Sci. U.S.A. 97, 5621-5626. doi: 10.1073/pnas.090504197

Zhang, L., Li, S., Chen, L., Li, J., Zhang, Z., Yang, Y., et al. (2019). Cerebellar fastigial nucleus electrical stimulatin protects against cerebral ischemic damage by upregulating telomerase activity. Restor. Neurol. Neurosci. 37, 131-141. doi: 10.3233/RNN- 180876

Zhou, H., Lin, Z., Voges, K., Ju, C., Gao, Z., Bosman, L. W., et al. (2014). Cerebellar modules operate at different frequencies. eLife 3:e02536. doi: 10.7554/elife. 02536

Zordan, P., Croci, L., Hawkes, R., and Consalez, G. G. (2008). Comparative analysis of proneural gene expression in the embryonic cerebellum. Dev. Dyn. 237, 1726-1735. doi: 10.1002/dvdy.21571

Conflict of Interest: The authors declare that the research was conducted in the absence of any commercial or financial relationships that could be construed as a potential conflict of interest.

Copyright $(02019$ Gill and Sillitoe. This is an open-access article distributed under the terms of the Creative Commons Attribution License (CC BY). The use, distribution or reproduction in other forums is permitted, provided the original author(s) and the copyright owner(s) are credited and that the original publication in this journal is cited, in accordance with accepted academic practice. No use, distribution or reproduction is permitted which does not comply with these terms. 